\title{
Calcium Application Enhances Drought Stress Tolerance in Sugar Beet and Promotes Plant Biomass and Beetroot Sucrose Concentration
}

\author{
Seyed Abdollah Hosseini *®D, Elise Réthoré, Sylvain Pluchon, Nusrat Ali ${ }^{\circledR}$, Bastien Billiot \\ and Jean-Claude Yvin \\ Plant Nutrition Department, Centre Mondial de l'Innovation Roullier, 35400 Saint Malo, France \\ * Correspondence: seyedabdollah.hosseini@roullier.com; Tel.: +33-2-9920-5831
}

Received: 20 June 2019; Accepted: 31 July 2019; Published: 2 August 2019

\begin{abstract}
Numerous studies have demonstrated the potential of sugar beet to lose the final sugar yield under water limiting regime. Ample evidences have revealed the important role of mineral nutrition in increasing plant tolerance to abiotic stresses. Despite the vital role of calcium $\left(\mathrm{Ca}^{2+}\right)$ in plant growth and development, as well as in stress responses as an intracellular messenger, its role in alleviating drought stress in sugar beet has been rarely addressed. Here, an attempt was undertaken to investigate whether, and to what extent, foliar application of $\mathrm{Ca}^{2+}$ confers drought stress tolerance in sugar beet plants exposed to drought stress. To achieve this goal, sugar beet plants, which were grown in a high throughput phenotyping platform, were sprayed with $\mathrm{Ca}^{2+}$ and submitted to drought stress. The results showed that foliar application of $\mathrm{Ca}^{2+}$ increased the level of magnesium and silicon in the leaves, promoted plant growth, height, and leaf coverage area as well as chlorophyll level. $\mathrm{Ca}^{2+}$, in turn, increased the carbohydrate levels in leaves under drought condition and regulated transcriptionally the genes involved in sucrose transport (BvSUC3 and BvTST3). Subsequently, $\mathrm{Ca}^{2+}$ enhanced the root biomass and simultaneously led to induction of root (BvSUC3 and BvTST1) sucrose transporters which eventually supported the loading of more sucrose into beetroot under drought stress. Metabolite analysis revealed that the beneficial effect of $\mathrm{Ca}^{2+}$ in tolerance to drought induced-oxidative stress is most likely mediated by higher glutathione pools, increased levels of free polyamine putrescine (Put), and lower levels of amino acid gamma-aminobutyric acid (GABA). Taken together, this work demonstrates that foliar application of $\mathrm{Ca}^{2+}$ is a promising fertilization strategy to improve mineral nutrition efficiency, sugar metabolism, redox state, and thus, drought stress tolerance.
\end{abstract}

Keywords: oxidative stress; metabolites; magnesium and silicon nutrition; carbohydrate synthesis

\section{Introduction}

Sugar beet (Beta vulgaris L.) is an industrial crop which belongs to the Chenopodiaceae family [1]. It provides nearly one-fifth of the sugar consumed in the world and it is also used as a significant source for the production of ethanol as bioenergy [1]. In sugar beet, sucrose comprises up to $18 \%$ of plant fresh weight which is the major form of reduced carbon involved in long-distance transport in most crop plants [2]. During photosynthesis, starch is synthesized and stored in the chloroplast matrix and sucrose is synthesized in the leaf cytosol, and through phloem transport is allocated to sink tissues where it can accumulate to high concentrations [3].

Drought is one of the major limiting factors for crop production. The reduction of sugar beet yield has been frequently reported under water limiting conditions [4,5]. The potential reduction of 5 to $30 \%$ of sugar beet production in Europe, has been estimated under current limitation of water 
resources [6]. Drought induces diverse physiological and biochemical changes in crop plants. The first consequence of drought is stomatal closure which can reduce water potential resulting in an inhibition of carbon dioxide uptake, photosynthesis, and subsequent reduction in carbohydrate production and its allocation to the root organ [7]. Another early consequence of low water availability under drought is a decrease in total nutrient uptake and translocation to shoots [8]. This results mainly from a reduced transpirational flow and hence a decreased mass flow to the root surface of soil water containing soluble nutrients like potassium $(\mathrm{K})$, nitrogen $(\mathrm{N})$, and $\mathrm{Ca}^{2+}[9]$. Therefore, it is crucial to maintain the proper uptake of mineral nutrition and functioning of photosynthetic machinery in order to prevent the losses of sugar yield under such a harsh condition.

In general, plants evolve various physiological, morphological, and biochemical responses to cope with drought stress [10]. Among the physiological responses, the protective effect of plant growth regulators and osmoprotectants like free amino acids, sugars, and polyamines, has been well documented [11]. Moreover, the role of mineral nutrition in alleviation of drought stress has widely been shown in crop plants. As an example, foliar application of $\mathrm{K}$ together with $\mathrm{N}$ and phosphorus $(\mathrm{P})$ enhanced grain yield in wheat under drought stress [12]. Sugar beet has the highest nutrient demands. Besides the main nutrients such as $\mathrm{N}, \mathrm{P}, \mathrm{K}$, magnesium $(\mathrm{Mg})$, and sulfur (S), sugar beet also needs trace minerals such as boron and manganese. Among these minerals, $\mathrm{K}$ and $\mathrm{Mg}$ play vital roles in sugar beet growth and development due to their involvement in the photosynthetic activity, sugar synthesis, and its efficient transport into the beetroot as storage organ [13,14]. In addition, as an essential plant nutrient, $\mathrm{Ca}^{2+}$ plays a vital role in plant growth and development, like structural roles in the cell wall and membranes, counter-cation for inorganic and organic anions in the vacuole, and as an intracellular messenger in the cytosol [15]. Increasing evidences have also indicated the importance of $\mathrm{Ca}^{2+}$ in the regulation of photosynthesis [15-20]. In these studies, the function of the involved proteins in photosynthesis machinery as well as their $\mathrm{Ca}^{2+}$ dependency have been investigated. It is worthy to note that the role of $\mathrm{Ca}^{2+}$ in alleviating drought stress has also been studied in different plants like Arabidopsis thaliana [21] and maize [22]. So far, this relation has rarely been addressed in sugar beet, leaving open whether and to what extent the $\mathrm{Ca}^{2+}$ nutritional status protects carbohydrate metabolism and loss of sugar in beetroot from drought stress and how it might modulate the regulation of the primary metabolites and impact on the expression of the genes involved in sugar transport mainly SWEET-type and SUT/SUC transporters.

Therefore, to address the role of $\mathrm{Ca}^{2+}$ in drought stress in sugar beet, a sugar beet genotype was selected and submitted to drought stress in order to evaluate the effectiveness and relation of a Ca-product and stress tolerance in sugar beet. We hypothesized that drought stress would negatively impact plant growth and metabolism and inhibit the loading of sucrose to the beetroots, thus lowering sugar yield. The foliar application of $\mathrm{Ca}^{2+}$ to drought-stressed sugar beet, enhances the chlorophyll level and plant biomass, increases the synthesis of sucrose in leaves and its loading to storage root, thus mitigating drought stress responses. Therefore, investigating plant growth parameters as well as plant mineral status and changes in primary metabolites pointed to a vital role of $\mathrm{Ca}^{2+}$ under drought stress.

\section{Results}

\subsection{Foliar Application of $\mathrm{Ca}^{2+}$ Promoted Sugar Beet Growth, Chlorophyll Concentration, Plant Height, and Leaf Coverage Area under Drought Stress}

The impact of water stress was evaluated through a set of parameters related to growth, measured on beetroot and leaves at 35 days after first $\mathrm{Ca}^{2+}$ application (DAA). Drought stress did not provoke a particular change in beetroot dry weight (DW) as well as beetroot diameter compared to the control plants (Figure 1A,B). Interestingly, the foliar application of $\mathrm{Ca}^{2+}$ increased beetroot dry weight $(54 \%)$ under drought stress compared to control and drought stress alone (Figure 1A). This increase was also statistically significant for beetroot diameter (Figure 1B). In shoot, except a slight decrease in 
dry weight, the imposition of drought alone did not have any significant effect on shoot dry weight compared with that in control (Figure 1C). This slight decrease in shoot dry weight between control and drought stress encouraged us to verify that drought stress was sufficiently applied in our trial. Therefore, the expression levels of choline monooxygenase (BvCMO) and dehydration responsive element-binding 2A (BvDREB2A) as drought stress markers in sugar beet were examined. Expression of both genes were induced under drought stress alone compared to control (Supplementary Figure S1) displaying that drought stress was sufficiently induced. Like in beetroot, the foliar application of $\mathrm{Ca}^{2+}$ significantly increased the shoot dry weight in comparison with control and drought alone (Figure 1C). Next, the level of chlorophyll was determined as a physiological marker for drought stress. The chlorophyll concentration was slightly decreased in drought-stressed plants in comparison to control (Figure 1D). Nevertheless, the foliar application of $\mathrm{Ca}^{2+}$ significantly augmented the level of chlorophyll compared to control and drought stress alone (Figure 1D).
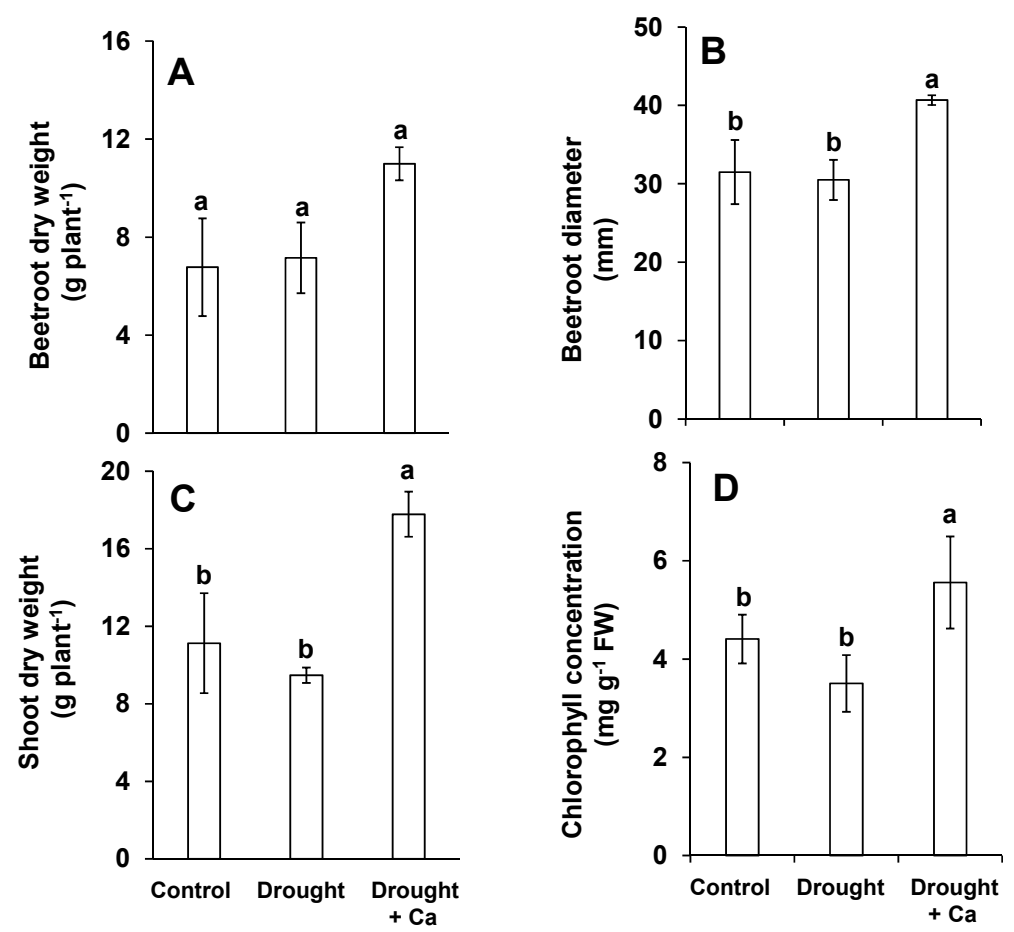

Figure 1. Influence of foliar application of $\mathrm{Ca}^{2+}$ on sugar beet root and shoot biomass and chlorophyll concentration under drought stress. (A) Beetroot dry weight; (B) beetroot diameter; (C) shoot dry weight; (D) chlorophyll concentration. Plants were grown in pots for a duration of 8 weeks. Five-week-old sugar beet plants were kept at $90 \%$ field capacity as control or exposed to drought stress (30\% field capacity) for a duration of 3 weeks. $\mathrm{Ca}^{2+}$ was applied at BBCH14 and BBCH18 in concentration of $5 \mathrm{~L} \mathrm{ha}^{-1}$ corresponding to $540 \mathrm{~g} \mathrm{Ca} \mathrm{ha}^{-1}$. Leaves and beetroot were harvested at 60 days after sowing for biomass and chlorophyll analysis. Bars indicate means \pm SD. Different letters denote significant differences according to ANOVA followed by SNK test $(p<0.05 ; n=6)$.

During plant growth and every 4 days after application of $\mathrm{Ca}^{2+}$, both plant height and leaf coverage area were monitored in Roullier's high-throughput plant phenotyping platform (Figure 2A). Plant height did not differ between control and drought stress alone up to 20 DAA of $\mathrm{Ca}^{2+}$ (Figure 2B). From day 24, the plant height tended to decline under drought stress alone which reached to the maximum reduction at day 34 after $\mathrm{Ca}^{2+}$ application (Figure 2B). The positive effect of $\mathrm{Ca}^{2+}$ on plant height was already visible at $12 \mathrm{DAA}$ of $\mathrm{Ca}^{2+}$, where this trait was positively increased in drought-stressed plants up to the end of trial (Figure 2B). Moreover, the leaf coverage area was increased under drought stress from the beginning of foliar application of $\mathrm{Ca}^{2+}$ (3 DAA) compared to control and drought alone and this increase was accelerated at 24 DAA till end of the experiment 
(Figure 2C). Altogether, these results indicate that foliar application of $\mathrm{Ca}^{2+}$ has a positive effect on biomass of sugar beet subjected to drought stress.

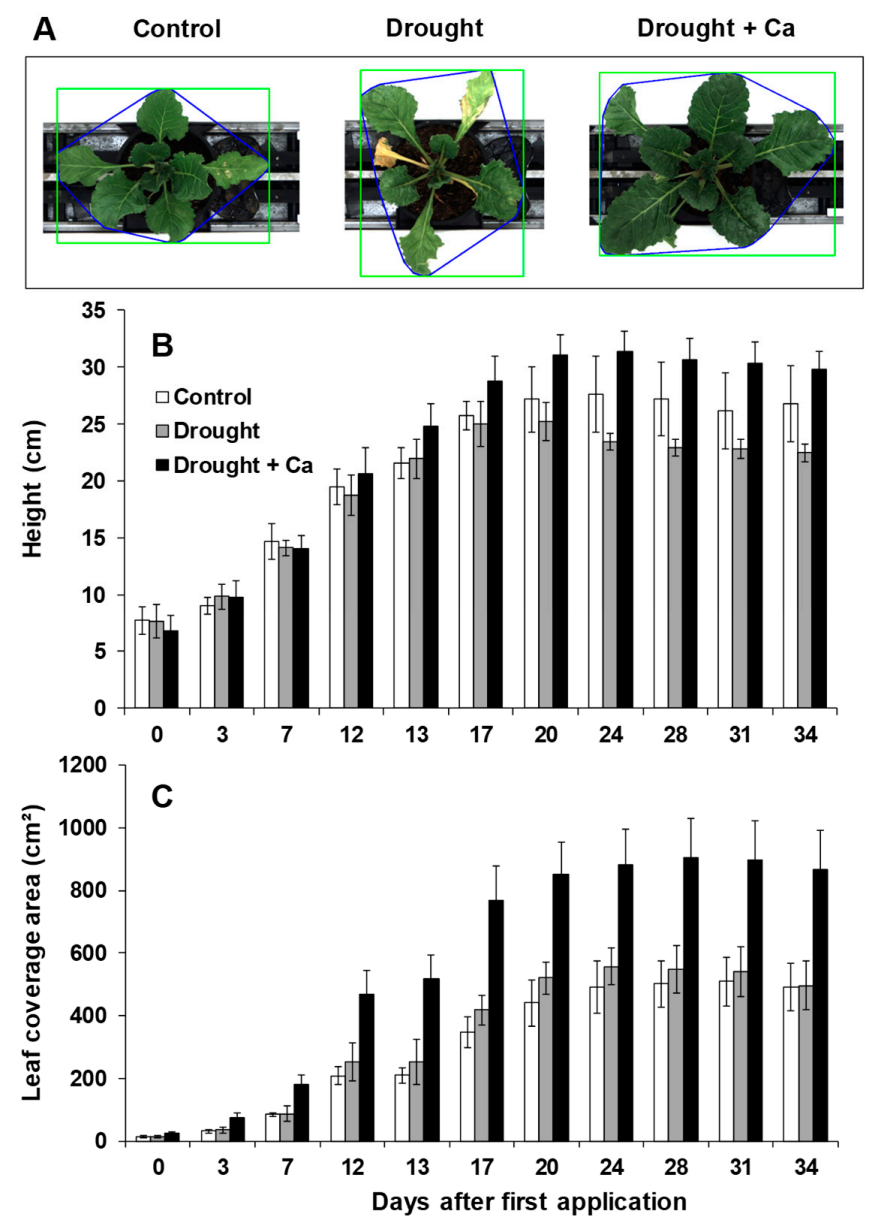

Figure 2. Influence of foliar application of $\mathrm{Ca}^{2+}$ on sugar beet leaf coverage area shape and height under drought stress. (A) Representative image-based detection of leaf coverage area; (B) plant height estimation based on lateral imaging; and (C) leaf coverage area. Plants were grown in pots for a duration of 8 weeks. Five-week-old sugar beet plants were kept at $90 \%$ field capacity as control or exposed to drought stress (30\% field capacity) for a duration of 3 weeks. $\mathrm{Ca}^{2+}$ was applied at BBCH14 and BBCH18 in concentration of $5 \mathrm{~L} \mathrm{ha}^{-1}$ corresponding to $540 \mathrm{~g} \mathrm{Ca} \mathrm{ha}^{-1}$. Plants were imaged every four days from first $\mathrm{Ca}^{2+}$ application. Bars indicate means $\pm \mathrm{SD}$.

\subsection{Foliar Application of $\mathrm{Ca}^{2+}$ Increased the Concentration of Magnesium $(\mathrm{Mg})$ and Silicon (Si) in Sugar Beet} Leaves under Drought Stress

To evaluate the nutritional status of sugar beet plants in response to foliar application of $\mathrm{Ca}^{2+}$, elemental profiling was performed for both beetroot and leaf samples. We did not observe any particular changes for both macro and micro-elements in beetroot of both control and drought-stressed plants (Table 1). In general, the level of macro-elements did not fall below the optimum needs of sugar beet. We did not observe any particular changes in the level of $\mathrm{N}$ in both beetroot and leaf organs under drought (Table 1). The remarkable changes in the nutritional analysis were found in drought-stressed plants when $\mathrm{Ca}^{2+}$ was sprayed. Among macro-elements, foliar application of $\mathrm{Ca}^{2+}$ significantly decreased the concentrations of both $\mathrm{P}$ and $\mathrm{K}$ in beetroots compared to the control and drought-stressed plants which were not sprayed with $\mathrm{Ca}^{2+}$ (Table 1). This trend also held true for micro-elements iron, manganese, zinc, and copper. In leaves, concentrations of both $\mathrm{P}$ and $\mathrm{K}$ were decreased in drought-stressed plants with foliar application of $\mathrm{Ca}^{2+}$ compared to both control and drought alone (Table 1). We did not observe any consistent changes in the levels of beetroot $\mathrm{Mg}$ and $\mathrm{Si}$ 
with the foliar application of $\mathrm{Ca}^{2+}$ (Table 1). However, a significant increase in the levels of $\mathrm{Mg}$ and Si was observed in the leaves of drought-stressed plants in comparison to control and drought alone (Figure 3A,B). Like N, the concentration of Na did not change in the current study. However, due to an important role of $\mathrm{Na}$ in sugar beet growth, the $\mathrm{Na} / \mathrm{K}$ ratio was calculated in both beetroot and leaf (Table 1). The changes were not statistically confirmed, however, in leaf and under drought stress, the $\mathrm{Na} / \mathrm{K}$ ratio increased nearly $40 \%$ compared to control and drought stress alone (Table 1 ).
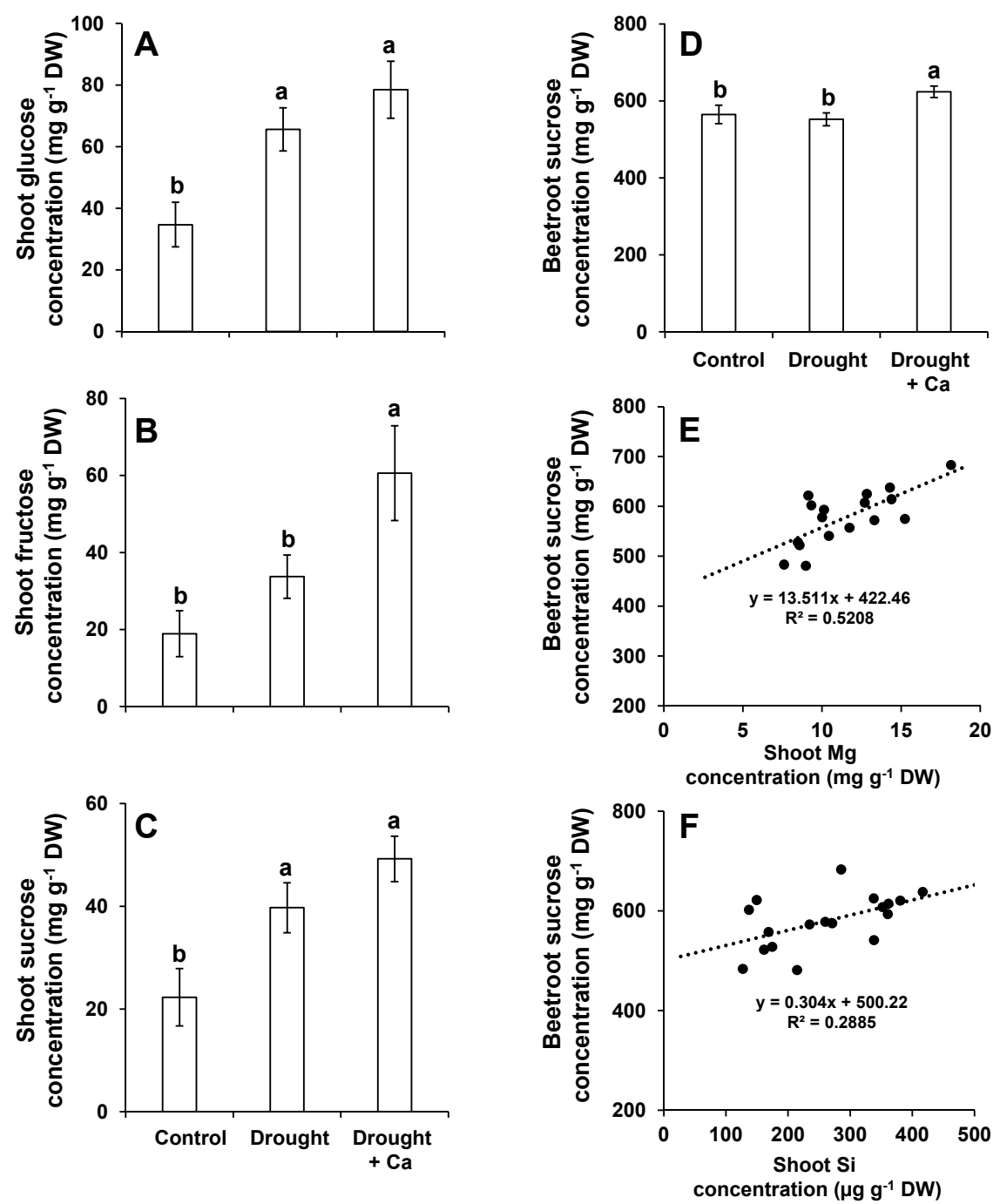

Figure 3. Influence of foliar application of $\mathrm{Ca}^{2+}$ on soluble sugar concentration in sugar beet exposed to drought stress. (A) Shoot glucose concentration; (B) shoot fructose concentration; (C) shoot sucrose concentration; (D) beetroot sucrose concentration; (E) correlation between beetroot sucrose content and shoot Mg content; and (F) correlation between beetroot sucrose content and shoot Si content. Plants were grown in pots for a duration of 8 weeks. Five-week-old sugar beet plants were kept at $90 \%$ field capacity as control or exposed to drought stress ( $30 \%$ field capacity) for a duration of 3 weeks. $\mathrm{Ca}^{2+}$ was applied at BBCH14 and BBCH18 in concentration of $5 \mathrm{~L} \mathrm{ha}^{-1}$ corresponding to $540 \mathrm{~g} \mathrm{Ca} \mathrm{ha}^{-1}$. Leaves and beetroot were harvested at 60 days after sowing for soluble sugars analysis. Bars indicate means \pm SEM. Different letters denote significant differences according to ANOVA followed by SNK test $(p<0.05 ; n=6)$. 
Table 1. Influence of foliar application of $\mathrm{Ca}^{2+}$ on the beetroot and leaf elemental composition in sugar beet plants exposed to drought stress. Plants were grown in pots for a duration of 8 weeks. Five-week-old sugar beet plants were kept at $90 \%$ field capacity as control or exposed to drought stress (30\% field capacity) for a duration of 3 weeks. $\mathrm{Ca}^{2+}$ was applied at BBCH14 and BBCH18 in concentration of $5 \mathrm{~L} \mathrm{ha}^{-1}$ corresponding to $540 \mathrm{~g} \mathrm{Ca} \mathrm{ha}^{-1}$. Leaves and beetroot were harvested at 60 days after sowing for elemental analysis. Bars indicate means \pm SEM. Different letters denote significant differences according to ANOVA followed by SNK test $(p<0.05 ; n=6)$ and ns denotes non-significant differences. Abbreviations are: $\mathrm{N}$, nitrogen; $\mathrm{K}$, potassium; $\mathrm{P}$, phosphorus; $\mathrm{Mg}$, magnesium; $\mathrm{Ca}$, calcium; $\mathrm{S}$, sulfur; $\mathrm{Na}$, sodium; Mn, manganese; Zn, zinc; Fe, iron; B, boron; $\mathrm{Cu}$, copper; and Si, silicon.

\begin{tabular}{|c|c|c|c|c|c|c|c|}
\hline & & \multicolumn{3}{|c|}{ Beetroot (mg g ${ }^{-1}$ DW) } & \multicolumn{3}{|c|}{ Leaves (mg g ${ }^{-1}$ DW) } \\
\hline & & Control & Drought & Drought + Ca & Control & Drought & Drought $+\mathrm{Ca}$ \\
\hline \multirow{4}{*}{ Macro-elements } & $\mathrm{N}$ & $8.45 \pm 0.60^{b}$ & $9.07 \pm 0.75^{a b}$ & $9.53 \pm 0.19^{a}$ & $28.05 \pm 4.98^{\mathrm{ns}}$ & $26.22 \pm 7.25^{\mathrm{ns}}$ & $30.16 \pm 4.03^{\mathrm{ns}}$ \\
\hline & $\mathrm{P}$ & $4.21 \pm 0.46^{\mathrm{a}}$ & $4.20 \pm 0.65^{\mathrm{a}}$ & $3.01 \pm 0.08^{b}$ & $17.24 \pm 6.96^{\mathrm{a}}$ & $15.51 \pm 5.33^{\mathrm{a}}$ & $8.11 \pm 1.41^{\mathrm{b}}$ \\
\hline & $\mathrm{Mg}$ & $1.70 \pm 0.30^{\mathrm{ns}}$ & $1.78 \pm 0.19^{\mathrm{ns}}$ & $1.68 \pm 0.06^{\mathrm{ns}}$ & $9.30 \pm 0.70^{b}$ & $10.22 \pm 2.09^{b}$ & $14.61 \pm 1.99^{\mathrm{a}}$ \\
\hline & $\mathrm{Ca}$ & $1.46 \pm 0.10^{\mathrm{ns}}$ & $1.49 \pm 0.04^{\mathrm{ns}}$ & $1.37 \pm 0.09 \mathrm{~ns}$ & $12.22 \pm 2.62^{\mathrm{ns}}$ & $11.35 \pm 2.08^{\mathrm{ns}}$ & $13.11 \pm 1.24^{\mathrm{ns}}$ \\
\hline \multirow{5}{*}{ Micro-elements } & $\mathrm{Mn}$ & $0.051 \pm 0.035^{\mathrm{ab}}$ & $0.083 \pm 0.053^{\mathrm{a}}$ & $0.012 \pm 0.002^{b}$ & $0.454 \pm 0.331^{\mathrm{a}}$ & $0.543 \pm 0.401^{\mathrm{a}}$ & $0.051 \pm 0.005^{b}$ \\
\hline & $\mathrm{Zn}$ & $0.038 \pm 0.007^{\mathrm{a}}$ & $0.043 \pm 0.007^{\mathrm{a}}$ & $0.030 \pm 0.003^{b}$ & $0.313 \pm 0.190^{\mathrm{a}}$ & $0.167 \pm 0.045 \mathrm{ab}$ & $0.113 \pm 0.004^{b}$ \\
\hline & $\mathrm{Fe}$ & $0.017 \pm 0.002^{b}$ & $0.025 \pm 0.007^{\mathrm{a}}$ & $0.016 \pm 0.002^{b}$ & $0.070 \pm 0.007^{\mathrm{ns}}$ & $0.070 \pm 0.005^{\mathrm{ns}}$ & $0.073 \pm 0.006^{\mathrm{ns}}$ \\
\hline & B & $0.014 \pm 0.001^{\mathrm{ns}}$ & $0.015 \pm 0.001^{\mathrm{ns}}$ & $0.013 \pm 0.002^{\mathrm{ns}}$ & $0.058 \pm 0.014^{\mathrm{ns}}$ & $0.060 \pm 0.014^{\mathrm{ns}}$ & $0.065 \pm 0.006^{\mathrm{ns}}$ \\
\hline & $\mathrm{Cu}$ & $0.007 \pm 0.001^{\mathrm{a}}$ & $0.007 \pm 0.001^{\mathrm{a}}$ & $0.005 \pm 0.0004^{b}$ & $0.019 \pm 0.005^{\mathrm{a}}$ & $0.013 \pm 0.003^{\mathrm{ab}}$ & $0.009 \pm 0.001^{b}$ \\
\hline Beneficial & $\mathrm{Si}$ & $0.010 \pm 0.003^{\mathrm{ns}}$ & $0.009 \pm 0.002^{\mathrm{ns}}$ & $0.009 \pm 0.002^{\mathrm{ns}}$ & $0.230 \pm 0.104^{b}$ & $0.221 \pm 0.084^{b}$ & $0.338 \pm 0.053^{\mathrm{a}}$ \\
\hline
\end{tabular}

We also observed a significant reduction in the levels of both zinc and copper under drought stress when $\mathrm{Ca}^{2+}$ was supplied (Table 1 ). The results showed that the foliar application of $\mathrm{Ca}^{2+}$ decreased the accumulation of mineral nutrients in the beetroot while it increased the level of macro-elements $\mathrm{Mg}$ and $\mathrm{Si}$ in leaves.

\subsection{Foliar Application of $\mathrm{Ca}^{2+}$ Increased the Concentration of Sugars in Beetroot and Leaves Exposed to Drought Stress and Induced the Expression of the Genes Involved in Sugar Transport}

In the next approach, the concentrations of soluble sugars, particularly sucrose (Suc) as a major economical part of sugar beet, were determined. In general, drought stress alone increased the levels of leaf Glu, Fru, and Suc compared to the control and this increase was not statistically significant for Fru (Figure 3A-C). Interestingly, under drought condition, foliar application of $\mathrm{Ca}^{2+}$ increased the level of Glu, Fru, and Suc by 20\%, 80\%, and 24\%, respectively, when compared to drought alone (Figure 3A-C). The beetroot Suc levels did not differ between control and drought-stress plants, while foliar application of $\mathrm{Ca}^{2+}$ significantly increased its level by $13 \%$ under drought stress (Figure 3D).

Given that Suc concentration increased in beetroot, we analyzed the correlation between beetroot sucrose concentration and both $\mathrm{Mg}$ and $\mathrm{Si}$ levels in leaves. The positive correlation was observed between $\mathrm{Mg}$ concentration in leaves and Suc concentration in beetroot $\left(R^{2}=0.52\right)$ (Figure 3E). This correlation was also positive in a lesser extent for Si concentration in leaves and Suc concentration in beetroot $\left(R^{2}=0.28\right)$ (Figure $\left.3 F\right)$.

The impact of foliar spray of $\mathrm{Ca}^{2+}$ on drought-stressed sugar beet was also evaluated at the molecular level by monitoring the expression of the genes related to phloem and cellular export/loading of Suc, SWEET-type, and SUT/SUC transporters. In beetroots, the expression level of BvSUC3 was approximately the same in control and drought stress alone (Figure 4A), whereas the expression level of this gene was significantly up-regulated by foliar application of $\mathrm{Ca}^{2+}$. In addition, the expression level of BvTST1 was significantly induced under drought stress irrespective of the foliar application of $\mathrm{Ca}^{2+}$ and this induction was more pronounced in drought-stressed plants supplied with Ca ${ }^{2+}$ (Figure 4B). We did not observe any particular changes in the expression level of BvSUT1 in beetroot (Figure 4C). In leaves, transcript levels of BvSUC3 and BvTST3 did not differ between control and drought alone, 
while $\mathrm{Ca}^{2+}$ treatment significantly up-regulated the expression of both genes (Figure $4 \mathrm{D}, \mathrm{E}$ ). Moreover, we did not observe any significant differences for the expression pattern of BvSUT1 under drought stress irrespective of foliar $\mathrm{Ca}^{2+}$ application (Figure 4F). Nevertheless, BvSUT1 expression was slightly, but not significantly, up-regulated under drought in Ca-treated plants compared to control plants (Figure 4F).
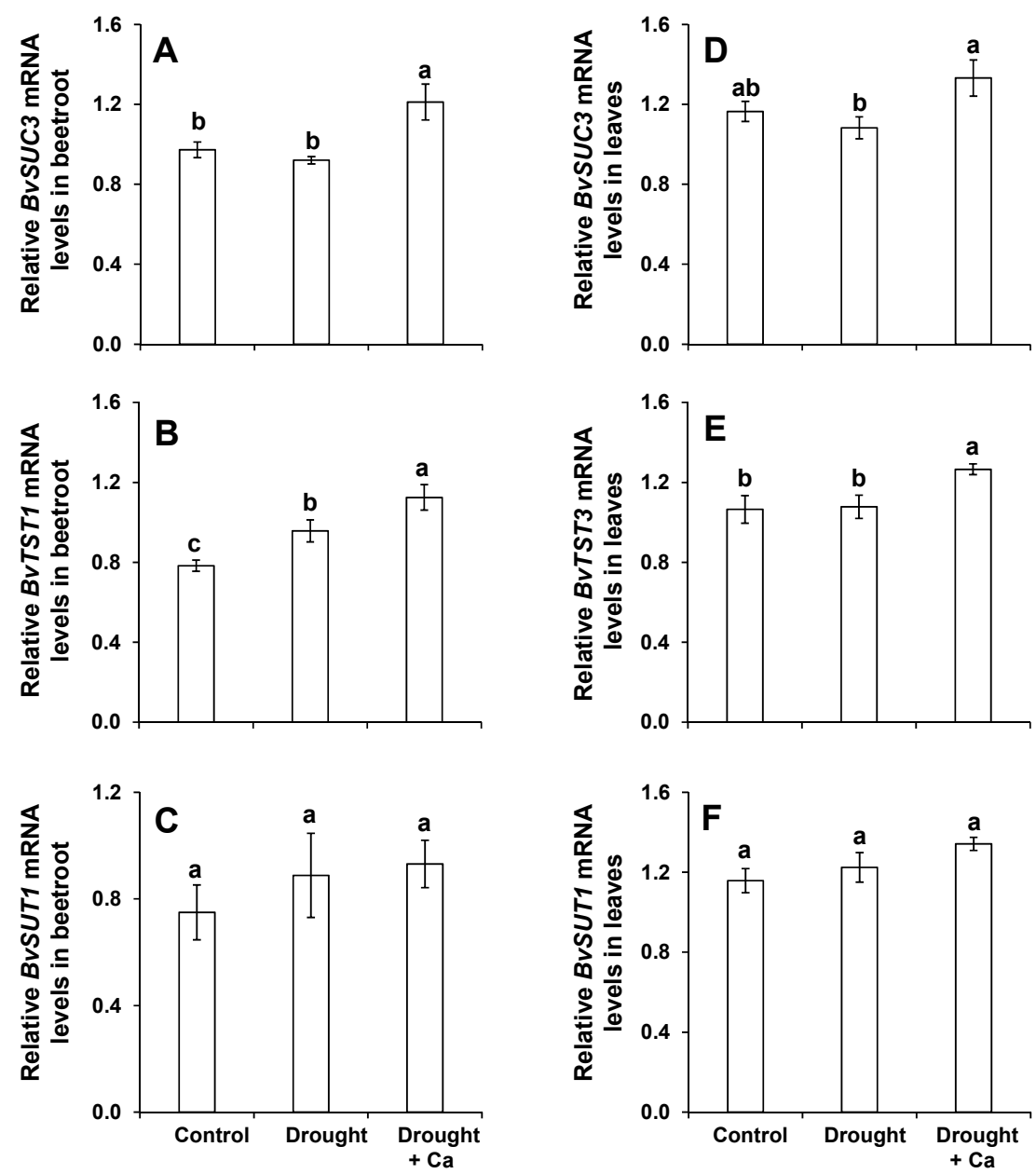

Figure 4. Influence of foliar application of $\mathrm{Ca}^{2+}$ on the expression levels of the genes involved in sugar transport in sugar beet plants exposed to drought stress. (A) Relative BvSUC3 mRNA levels in beetroot; (B) relative BvTST1 mRNA levels in beetroot; (C) relative BvSUT1 mRNA levels in beetroot; (D) relative BvSUC3 mRNA levels in leaves; (E) relative BvTST3 mRNA levels in leaves; and (F) relative BvSUT1 mRNA levels in leaves. Plants were grown in pots for a duration of 8 weeks. Five-week-old sugar beet plants were kept at $90 \%$ field capacity as control or exposed to drought stress ( $30 \%$ field capacity) for a duration of 3 weeks. $\mathrm{Ca}^{2+}$ was applied at BBCH14 and BBCH18 in concentration of $5 \mathrm{~L}$ $\mathrm{ha}^{-1}$ corresponding to $540 \mathrm{~g} \mathrm{Ca} \mathrm{ha}^{-1}$. Leaves and beetroot were harvested at 60 days after sowing for gene expression analysis. Bars indicate means \pm SEM. Different letters denote significant differences according to ANOVA followed by SNK test $(p<0.05 ; n=6)$.

\subsection{Foliar Application of $\mathrm{Ca}^{2+}$ Modulated Plant Primary Metabolites under Drought Stress}

Because of the important role of metabolites in drought stress tolerance, the effect of $\mathrm{Ca}^{2+}$ was further investigated on primary metabolites, mainly those compounds which are involved in stress responses. In beetroots, and compared to control plants, the concentration of glutamate (Glu) was decreased under drought irrespective of foliar application of $\mathrm{Ca}^{2+}$ (Figure 5A). While, a significant increase in the levels of glutamine (Gln), lysine (Lys), and leucine (Leu) was observed in drought-stressed plants which were sprayed with $\mathrm{Ca}^{2+}$ when compared to control and drought 
alone (Supplementary Table S1). Also, the levels of isoleucine (Ile), tryptophan (Trp) (Supplementary Table S1), and gamma-aminobutyric acid (GABA) (Figure 5B) were increased under drought in spite of the foliar application of $\mathrm{Ca}^{2+}$ and this increase was statistically significant compared to the control plants. In leaves and unlike the beetroots, a positive significant impact of $\mathrm{Ca}^{2+}$ on the levels of Glu was observed in comparison to drought alone (Figure 5A and Supplementary Table S1). Moreover, the levels of histidine (His), Trp, and GABA was significantly increased under drought alone, but decreased to the same levels of the control in drought-stressed plants treated with $\mathrm{Ca}^{2+}$ (Figure 5B and Supplementary Table S1).
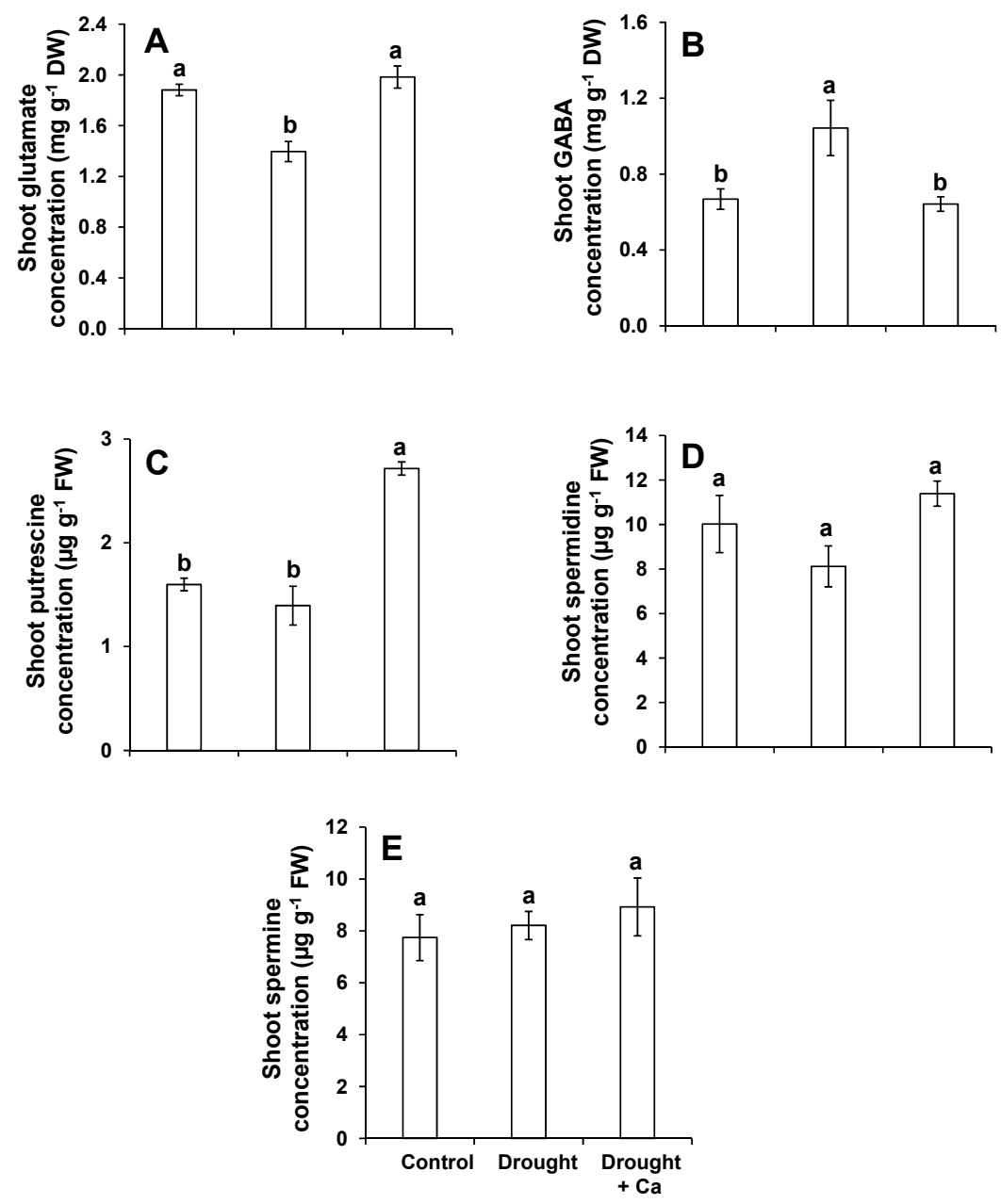

Figure 5. Influence of foliar application of $\mathrm{Ca}^{2+}$ on shoot glutamate, GABA, and polyamine concentrations in sugar beet plants exposed to drought stress. (A) Shoot glutamate concentration; (B) shoot GABA concentration; (C) shoot putrescine concentration; (D) shoot spermidine concentration; and (E) shoot spermine concentration. Plants were grown in pots for a duration of 8 weeks. Five-week-old sugar beet plants were kept at $90 \%$ field capacity as control or exposed to drought stress (30\% field capacity) for a duration of 3 weeks. $\mathrm{Ca}^{2+}$ was applied at BBCH14 and BBCH18 in concentration of $5 \mathrm{~L} \mathrm{ha}^{-1}$ corresponding to $540 \mathrm{~g} \mathrm{Ca} \mathrm{ha}^{-1}$. Leaves and beetroot were harvested at 60 days after sowing for metabolite analysis. Bars indicate means \pm SEM. Different letters denote significant differences according to ANOVA followed by SNK test $(p<0.05 ; n=6)$.

Among the beetroot organic acids, the concentration of citrate was significantly decreased under drought stress in the presence of $\mathrm{Ca}^{2+}$ and in comparison to drought alone (Supplementary Table S1). In leaves, the level of isocitrate was significantly increased with foliar application of $\mathrm{Ca}^{2+}$ compared to the other treatments (Supplementary Table S1). In addition, the level of malate was increased 
under drought stress irrespective of the foliar application of $\mathrm{Ca}^{2+}$ in comparison to the control plants (Supplementary Table S1).

Monitoring the level of polyamines, metabolites, which are involved in stress responses in plants [23], showed a significant increase in the concentration of putrescine in leaves with foliar application of $\mathrm{Ca}^{2+}$ compared to control and drought stress alone (Figure 5C). We did not observe any significant changes in the levels of leaf spermidine and spermine among the tested conditions (Figure 5D,E).

\subsection{Foliar Application of $\mathrm{Ca}^{2+}$ Regulated the Glutathione Pool under Drought Stress}

Balancing the redox state via glutathione pool is very critical under drought induced-oxidative stress [11]. Therefore, we measured both reduced (GSH) and oxidized (GSSG) glutathione, and calculated the GSSG/GSH ratio in leaves of control, drought stress alone and drought stress plants which did receive Ca. The GSH concentration was decreased under drought when compared to the control condition (Figure 6A). Interestingly, foliar application of $\mathrm{Ca}^{2+}$ significantly enhanced the concentrations of GSH in leaves under drought stress to a similar level of that in control (Figure 6A). As expected, the concentration of GSSG and its ratio to GSH (GSSG/GSH) were increased under drought alone compared to the control (Figure 6B,C). However, $\mathrm{Ca}^{2+}$ treatment strongly reduced their level to the same level of control plants (Figure 6B,C). We further examined the expression level of glutathione reductase ( $B v G R)$ as a key gene for recycling the GSSG to GSH for balancing the redox potential under stress conditions [11]. The expression of this gene was slightly, but not significantly, induced under drought stress by foliar spray of $\mathrm{Ca}^{2+}$ as compared to drought stress alone (Figure 6D). These results indicate that foliar application of $\mathrm{Ca}^{2+}$ mitigates drought stress-induced oxidative stress in sugar beet.
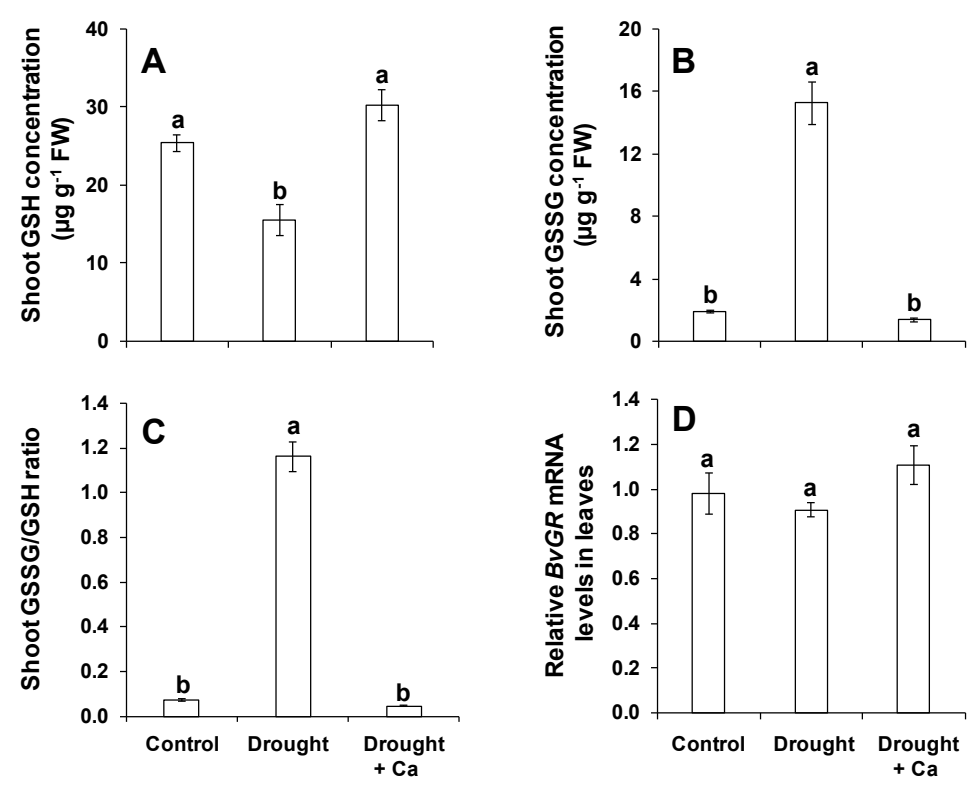

Figure 6. Influence of foliar application of $\mathrm{Ca}^{2+}$ on shoot glutathione pool and on the expression of glutathione reductase in sugar beet exposed to drought stress. (A) Shoot GSH concentration; (B) shoot GSSG concentration; (C) shoot GSSH/GSH ratio; and (D) relative BvGR mRNA levels in leaves. Plants were grown in pots for a duration of 8 weeks. Five-week-old sugar beet plants were kept at $90 \%$ field capacity as control or exposed to drought stress (30\% field capacity) for a duration of 3 weeks. $\mathrm{Ca}^{2+}$ was applied at BBCH14 and BBCH18 in concentration of $5 \mathrm{~L} \mathrm{ha}^{-1}$ corresponding to $540 \mathrm{~g} \mathrm{Ca} \mathrm{ha}^{-1}$. Leaves and beetroot were harvested at 60 days after sowing for glutathione analysis. Bars indicate means \pm SEM. Different letters denote significant differences according to ANOVA followed by SNK test $(p<0.05 ; n=6)$. 


\section{Discussion}

Strong evidences have demonstrated that plant mineral nutrition plays a vital role in mitigating drought stress in crop plants [8,24]. However, despite the important signaling role of $\mathrm{Ca}^{2+}$ in plant responses to different abiotic stresses [25], research for the beneficial role of $\mathrm{Ca}^{2+}$ in drought stress tolerance in sugar beet is not carefully considered. In our study, monitoring the responses of sugar beet to drought stress and foliar application of $\mathrm{Ca}^{2+}$ showed that the higher Suc in beetroot is associated with higher $\mathrm{Mg}$ and $\mathrm{Si}$ in leaves which positively augments the chlorophyll level and shoot biomass and increases the synthesis of soluble sugars. We clearly show that the application of $\mathrm{Ca}^{2+}$ to sugar beet plant could be a useful strategy to increase drought tolerance and to decrease beetroot sugar losses.

\subsection{Foliar Application of $\mathrm{Ca}^{2+}$ Increases $\mathrm{Mg}$ and Si Levels in Leaves and Promotes Plant Growth, Height, Leaf Coverage Area Parameters under Drought Stress}

The main consequence of drought stress is the restriction of plant growth and development. Increasing evidences have shown a growth reduction under drought stress in maize [26], and in other plants like A. thaliana [27], wheat [28], and rice [29]. In addition, the sensitivity of sugar beet to limited water supply has been previously reported [5-7]. For instance, Hoffmann et al., (2010) showed a reduction in both shoot and root dry matter in sugar beet subjected to drought stress [4]. They showed that the reduction in dry matter was more pronounced in the root organ. In the present work, both beetroot and shoot biomass as well as beetroot diameter responded positively to $\mathrm{Ca}^{2+}$ application under drought stress. Interestingly, the positive effect of $\mathrm{Ca}^{2+}$ was also held true for plant height and leaf coverage area. These results are in line with previous work on sugar beet, where the foliar application of both $\mathrm{Si}$ and $\mathrm{Ca}^{2+}$ increased the root and shoot biomass by $13 \%$ and $21 \%$, respectively [30]. The higher biomass in this study can be explained by the role of $\mathrm{Ca}^{2+}$ in stabilizing the structure of the organelles in photosynthetic machinery under drought condition [31].

Water scarcity also leads to a decrease in total nutrient uptake and translocation to the shoots [8]. Under such a condition, the plant's normal metabolism is restricted, which ultimately reduces crop yields [32]. Plant leaves have capacity to absorb water and nutrients, however, foliar spray of nutrients can be a good strategy to maintain crop yields and quality under conditions of limited soil nutrient as well as lack of available water [9]. In a study on Citrus macrophylla L. seedling, foliar application of potassium nitrate improved the tolerance to drought stress [33]. Also, exogenous $\mathrm{Ca}^{2+}$ was shown to alleviate the degree of photosynthesis pigment degradation and ensured normal photosynthesis in tobacco plant subjected to drought stress [34]. In our elemental profiling, $\mathrm{Ca}^{2+}$ application modulated distinct changes on the level of macro-elements: while the levels of N, Ca, S, and Na did not differ in beetroot and leaf, concentrations of both $\mathrm{K}$ and $\mathrm{P}$ decreased in beetroot and leaf by application of $\mathrm{Ca}^{2+}$. The decrease in the level of beetroot $\mathrm{K}$ and $\mathrm{P}$ may be due to a decrease in transpirational flow and hence a decreased mass flow and diffusion-driven nutrient transport under drought stress even if it was not evident in drought stress treatment alone [9,35]. In plants, a high proportion of the total $\mathrm{Ca}^{2+}$ is mainly located in the cell walls. Compared to monocotyledons, sugar beet has a large cation-exchange capacity as dicotyledon crops. Upon higher $\mathrm{Ca}^{2+}$ supply, excess $\mathrm{Ca}^{2+}$ is generally accumulated in the vacuole. This is similar in the case of $\mathrm{K}$ where vacuolar concentrations of $\mathrm{K}$ may reach up to $500 \mathrm{mM}$ [36]. The $\mathrm{K}$ concentration in the vacuoles can be replaced by other cations $\left(\mathrm{Na}^{+}\right.$, $\mathrm{Mg}^{2+}, \mathrm{Ca}^{2+}$ ) explaining why application of $\mathrm{Ca}^{2+}$ reduced the level of $\mathrm{K}$ in drought-stressed leaves in the present work [9]. Additionally, the lower concentrations of $\mathrm{K}$ and $\mathrm{P}$ in the leaf can be the result of lower uptake and translocation of these nutrients under drought condition which may cause uptake of other cations like $\mathrm{Mg}$ in non-specific cation absorption manner. Apparently, allocation of $\mathrm{Ca}^{2+}$ and $\mathrm{P}$ to separate cell types avoids the negative effect of precipitation of $\mathrm{Ca}-\mathrm{P}$, which would otherwise decline the availability of both nutrients [37]. Nevertheless, one might hypothesize that the observed decrease in the levels of leaf $\mathrm{K}$ and $\mathrm{P}$ after $\mathrm{Ca}^{2+}$ application serves potentially as a negative impact on the plant's growth. Conversely, looking to the average concentrations of $\mathrm{K}(>1 \%)$ and $\mathrm{P}(0.3-0.6 \%)$ in leaf, an adequate range of both elements for optimal growth and development of plant was observed. 
$\mathrm{Na}$ is another indispensable element which has stimulation effect on leaf growth in sugar beet. The role of $\mathrm{Na}$ in improving water relation under drought stress has also been well investigated [9]. The positive function of $\mathrm{Na}$ in response to drought stress was linked to its higher absorption under drought condition [38]. It has been shown that drought stress in Triplex canescens and Sesuvium portulacastrum was due to absorption of $\mathrm{Na}$ which was used directly for osmotic adjustment [38,39]. The involvement of $\mathrm{Na}$ in regulation of osmotic adjustment has been also shown in sugar beet plants imposed with osmotic stress [40]. In sugar beet, $\mathrm{Na}$ can be replaced by $\mathrm{K}$ to a large degree. The positive effect of Na on yield of sugar beet was shown in suboptimal concentration of K [41]. Hence, considering the low concentration of $\mathrm{K}$ under drought stress which was induced by $\mathrm{Ca}^{2+}$ supply, we assume that $\mathrm{Na}$ might play a role even if its levels did not change. This was confirmed by higher $\mathrm{Na} / \mathrm{K}$ ratio in shoot $(\sim 40 \%)$ indicating the possible role of $\mathrm{Na}$ in osmotic adjustment under drought stress and explaining to some extent the low concentration of $\mathrm{K}$ in leaf under drought by $\mathrm{Ca}^{2+}$ application.

As an indispensable divalent cation, $\mathrm{Mg}$ plays many vital roles in plants [42]. $\mathrm{Mg}$ is involved in energy metabolism and acts as an enzyme cofactor, carbohydrate partitioning, and enzyme activation [2,42]. It is also involved in the central atom of the chlorophyll molecule [9]. Under $\mathrm{Mg}$ deficiency, the necrosis spots appear in the young leaves due to the transport of $\mathrm{Mg}$ from old leaves, and thus breakdown of both plastid pigments and chlorophyll are increased $[13,43]$. In the present study, application of $\mathrm{Ca}^{2+}$ showed an increase in the level of $\mathrm{Mg}$ in the leaves which positively impacted on the levels of chlorophyll. This finding is in good agreement with a study in oregano (Origanum vulgare ssp. hirtum), where foliar application of $\mathrm{Ca}^{2+}$ increased the level of chlorophyll [44]. Ca-increased $\mathrm{Mg}$ concentration in leaf can be due to low concentration of leaf $\mathrm{K}$ as these two cations can be easily replaced [9]. This hypothesis was supported by a lower $\mathrm{Mg} / \mathrm{K}$ ratio in leaf (data not shown). Therefore, the higher leaf $\mathrm{Mg}$ induced by high $\mathrm{Ca}^{2+}$ and low $\mathrm{K}$ levels in one hand increased the chlorophyll level which maintained the photosynthetic machinery active. The proper functioning of photosynthesis led to substantial synthesis of soluble sugars in leaf and its translocation to beetroots, thus translated to higher biomass.

$\mathrm{Si}$ is another reported beneficial nutrient which has been shown to increase drought stress tolerance and mitigate mineral nutrient deficiency in crop plants [45]. For example, Si has been shown to increase root and shoot biomass under drought condition in xerophyte Zygophyllum xanthoxylum [46], tomato [47], and barley plants [24,48]. Moreover, foliar application of Si to Sorghum bicolor (L.) plant exposed to drought was shown to maintain a higher stomatal conductance and enhanced drought tolerance [49]. Numerous studies have also shown that Si addition to stressed plants significantly increased chlorophyll concentration and delayed leaf senescence [46,50-52]. In line with the above-mentioned studies, our study showed higher concentration of chlorophyll under drought after $\mathrm{Ca}^{2+}$ supply which could be due to an increase in the levels of leaf $\mathrm{Si}$. It is worth to note that $\mathrm{Ca}^{2+}$ application might have an indirect effect on leaf $\mathrm{Si}$ status and cross talk between these two elements and needs to be further experimentally investigated.

Altogether, our finding reveals that foliar application of $\mathrm{Ca}^{2+}$ had a positive effect on sugar beet plants under drought condition by mediating distinct changes in the levels of nutrients like $\mathrm{Mg}$ and $\mathrm{Si}$ in leaves, which caused an increase in chlorophyll and sugar levels and eventually enhanced plant growth and biomass.

\subsection{Foliar Application of $\mathrm{Ca}^{2+}$ Increases the Level of Soluble Sugars in Leaves and Beetroots and Induces the Genes Involved in Sucrose Transport}

The delivery of assimilates which results from leaf growth and photosynthesis is crucial for the accumulation of sucrose in storage root of sugar beet. In this regard, the improvement of plant growth by application of $\mathrm{Ca}^{2+}$ has further encouraged us to evaluate the changes in concentration of soluble sugars in the leaves and in the beetroot. A considerable reduction in the sucrose accumulation of beetroot in drought-stressed sugar beet has been already reported [53,54]. As an example, the work of Mäck and Hoffmann (2006) on sugar beet exposed to drought stress showed a reduction in 
sucrose concentration in beetroot due to the contribution of ions and other compatible solutes rather than a limitation in physical structure such as cambium rings [55]. To cope with drought stress, plants accumulate different compatible solutes, like amino acids or sugars to allow efficient osmotic adjustments [56,57]. The higher accumulation of Suc in the leaves of sugar beet as a result of drought stress can change the phloem loading process [55], which then induces leaf senescence, restricts water loss via transpiration [58], and downregulates photosynthesis [59]. In the present work, $\mathrm{Ca}^{2+}$ remarkably increased the concentrations of leaf soluble sugars Fru and particularly Suc under drought stress. Here, we also observed a significant increase (13\%) in beetroot Suc concentration under drought by foliar application of $\mathrm{Ca}^{2+}$. The higher levels of carbohydrate in leaves could be beneficial since it also serves an osmoticum under drought stress. Moreover, increased levels of sugars in the leaves and the loading of Suc to the beetroot can also be explained by the higher concentration of $\mathrm{Mg}$ and $\mathrm{Si}$ in the leaves. Indeed, previous studies have indicated that the shortage of $\mathrm{Mg}$ may restrict phloem loading of source in leaves resulting in growth constraint, particularly in roots [2,60-62]. However, in our work, the foliar application of $\mathrm{Ca}^{2+}$ resulted not only in higher concentrations of leaf $\mathrm{Mg}$, but also simultaneously enhanced the beetroot Suc concentrations. We also found that among the other solutes ( $\mathrm{K}, \mathrm{Na}$, amino acids), Suc was the major compound which accumulated in beetroot under drought condition when foliar application of $\mathrm{Ca}^{2+}$ was applied. Another explanation for higher Suc in beetroot could be due to the higher concentration of leaf Si. We have shown in our previous works in barley plants subjected to concomitant drought and mineral deficiencies (low $\mathrm{K}$ and low sulfur) that Si supply to the roots increased the sugar levels in shoots and allowed the loading of Suc into the roots [24,48]. In our earlier work, we have also shown that Si supplement, increased the levels of Si in maize plants grown under low $\mathrm{Mg}$ which turned to higher levels of soluble sugars in both leaves and roots [52]. Altogether, our findings indicate that foliar application of $\mathrm{Ca}^{2+}$ to drought-stressed sugar beet, increased the levels of $\mathrm{Mg}$ and $\mathrm{Si}$ in leaves underlying the capacity of the plants to produce more sugars in leaves as osmoticum which simultaneously loads the Suc into the beetroots.

The majority of Suc in taproot of sugar beet is stored in the vacuole [3] by carbohydrate partitioning where sugars are distributed from source leaves to the sink organs like roots [63]. This sucrose is like a reserve for plant growth and development and for synthesis of metabolite and energy particularly when plants are faced with biotic and abiotic stresses. Delivery of Suc within the plant cell is carried out with different sugar transporters mainly SWEET-type and SUT/SUC transporters [63]. In sugar beet, Jung et al. (2015) showed that BvTST2.1 correlated with the peak of higher Suc accumulation in the taproot [3]. This correlation has also been shown in other crop plants like sugarcane [64] and sweet sorghum [65]. Recently, in a study of A. thaliana plants grown in soil-based system, Durand et al., 2016 showed that drought stress induced the expression level of Suc phloem loading genes AtSWEET11, AtSWEET12, and AtSUC2 in the leaves [66]. These authors also showed an induction in the expression level of AtSUC2 and AtSWEET11 to AtSWEET15 in the roots. In line with the above-mentioned works, we showed that the expression levels of BvSUC 3 and BvTST1 induced in beetroot under drought stress with foliar application of $\mathrm{Ca}^{2+}$. The positive impact of $\mathrm{Ca}^{2+}$ on the expression pattern of BvSUC3 and BvTST3 was also detected in leaves. This indicates the putative role of $\mathrm{Ca}^{2+}$ in transcriptionally regulating the sugar transporters by allocating more Suc to the beetroot under drought condition.

\subsection{Foliar Application of $\mathrm{Ca}^{2+}$ Enhances Drought Tolerance in Sugar Beet by Regulating Glutathione Pools and Increasing Polyamine Putrescine}

Drought stress is considered to imply oxidative stress by disturbing the equilibrium between production of reactive oxygen species (ROS) and their detoxification [67]. Previous research has clearly demonstrated that plants exposed to drought stress triggered reactive oxygen species (ROS) production which ultimately impacts plant growth and development as a result of cell death $[67,68]$. However, plants evolve enzymatic and non-enzymatic defense mechanisms to cope with oxidative stress [69]. In addition, the regulation of ascorbate-glutathione cycle was also found to increase oxidative stress tolerance in different crop plants [70,71]. Under suboptimal water supply, the elevated levels of 
ROS result in the increase of oxidized glutathione (GSSG) in favor of reduced glutathione (GSH), thus inducing a higher GSSG/GSH ratio and results to severe oxidative stress [11,72]. The reduction in glutathione pools under drought stress has been shown in different crops like wheat [73], maize [70], and rice [74]. In line with the above-mentioned studies, the level of GSH significantly reduced under drought stress alone with a tandem increase in the concentrations of GSSG resulting in a higher GSSG/GSSG ratio. However, foliar application of $\mathrm{Ca}^{2+}$ significantly increased the level of GSH to the similar level of the control plants and sharply reduced the GSSG/GSH ratio under drought. This observation was interesting, since a low GSSG/GSH ratio is a critical factor under drought stress. This was further supported by the slight induction in $B v G R$ expression as a key factor for recycling the GSSG to GSH for balancing the redox state under stress conditions [11]. Our finding is also supported by our previous investigation in barley where root coped better with oxidative stress by implying a lower GSSG/GSH ratio and higher production of GSH [24]. This indicates that foliar application of $\mathrm{Ca}^{2+}$ positively balanced the glutathione pools and cellular redox homeostasis under drought stress which implicated lower oxidative stress.

The Ca-induced drought tolerance in sugar beet was further evaluated with regards to metabolite changes by focusing mainly on the polyamine pathway as well as amino acids. The role of polyamines in plant stress tolerance has been well reported in several studies [23,75]. In the present study, and among the polyamines, foliar application of $\mathrm{Ca}^{2+}$ significantly increased the levels of putrescine under drought stress. The higher concentration of putrescine can be associated with increased levels of Si when $\mathrm{Ca}^{2+}$ was sprayed to the drought-stressed sugar beet plants. We have shown in our previous works that Si modulates polyamines pathways in response to combined stresses [24,48] and Mg deficiency [52]. Moreover, we have reported that the application of $\mathrm{Si}$ to a drought-sensitive tomato line increased the levels of polyamines putrescine and spermine, leading to drought stress tolerance [47]. The cross talk between Si and polyamine pathways has also been shown in the Sorghum plant exposed to drought stress [76] where the levels of free putrescine, spermidine, and spermidine increased at the expense of ethylene.

It is also worth noting that in the leaves, the concentration of GABA enhanced significantly under drought stress. This increase was expected as the higher production of GABA is a common physiological response to drought stress [77]. However, foliar application of $\mathrm{Ca}^{2+}$ declined the GABA level under drought stress. These results indicated that sugar beet plants which were supplied with $\mathrm{Ca}^{2+}$ did not face severe stress and withstood water stress better than drought stress alone. Meanwhile, the concentration of glutamate (Glu) significantly increased under drought by foliar application of $\mathrm{Ca}^{2+}$. Both GABA and proline are synthesized from Glu which is the main pathway for their production under drought condition [77]. Glu is also involved in the production of free polyamines [78]. Notably, we have shown in our previous work that $\mathrm{Si}$ improved osmotic stress tolerance in drought-sensitive tomato line by increasing the production of Glu which was associated with higher synthesis of amino acid GABA and polyamine Put [47]. Hence, in the present work, the higher level of Glu by foliar application of $\mathrm{Ca}^{2+}$ could be due to the subsequent increase in the leaf $\mathrm{Si}$. Moreover, it seems, at least in our experimental condition, Glu influenced polyamine synthesis rather than production of stress amino acid GABA. This could be further supported as we did not observe any consistent changes in the level of proline. These results, on one hand, indicate that the Ca-treated plants most probably suffered less from drought and did not require an increase in the level of stress amino acids like GABA. On the other hand, $\mathrm{Ca}^{2+}$ allowed plants to cope better with drought stress since it positively modulated the polyamine pathway and increased the level of Put as a result of higher Glu synthesis.

\section{Materials and Methods}

\subsection{Seed Germination, Plant Material, and Stress Treatment}

Seeds of sugar beet (B. vulgaris L.) Marinella genotype was kindly provided by KWS via COPROB, Minerbio, Italy. Seeds were germinated on Podground H90 substrate (Klasmann, Bremen, Germany) 
for 16 days $\left(20 / 18{ }^{\circ} \mathrm{C}, 16 \mathrm{~h}\right.$ day, $80 \%$ relative humidity). The experiment was completely randomized and each treatment was represented by 6 replicate pots with one plant per pot. Plants were cultivated in $6.5 \mathrm{~L}$ pots (Pöppelmann, Lohne, Germany) using Substrate 5 GreenFibre (Klasmann). According to manufacturer, this substrate contains $180 \mathrm{mg} \mathrm{L}^{-1} \mathrm{~N}, 210 \mathrm{mg} \mathrm{L}^{-1} \mathrm{P}_{2} \mathrm{O}_{5}, 360 \mathrm{mg} \mathrm{L}^{-1} \mathrm{~K}_{2} \mathrm{O}, 100 \mathrm{mg} \mathrm{L}^{-1} \mathrm{Mg}$, and $150 \mathrm{mg} \mathrm{L}^{-1} \mathrm{~S}$. Foliar application of $\mathrm{Ca}^{2+}$ was performed five weeks after germination at $\mathrm{BBCH} 14$ and BBCH18 in a dose of $5 \mathrm{~L} \mathrm{ha}^{-1}$ corresponding to $540 \mathrm{~g} \mathrm{Ca} \mathrm{ha}^{-1}$ in each application using automated machine customized for spraying fertilizers (InoviaFlow, Dole, France). This product contained 15\% $\mathrm{CaO}\left(\mathrm{CaCl}_{2}\right)$. Drought stress (30\% field capacity) was imposed 2 days after the second application of $\mathrm{Ca}^{2+}$ for a duration of 3 weeks. Control plants were watered continuously and were kept at $90 \%$ field capacity (Figure 7).

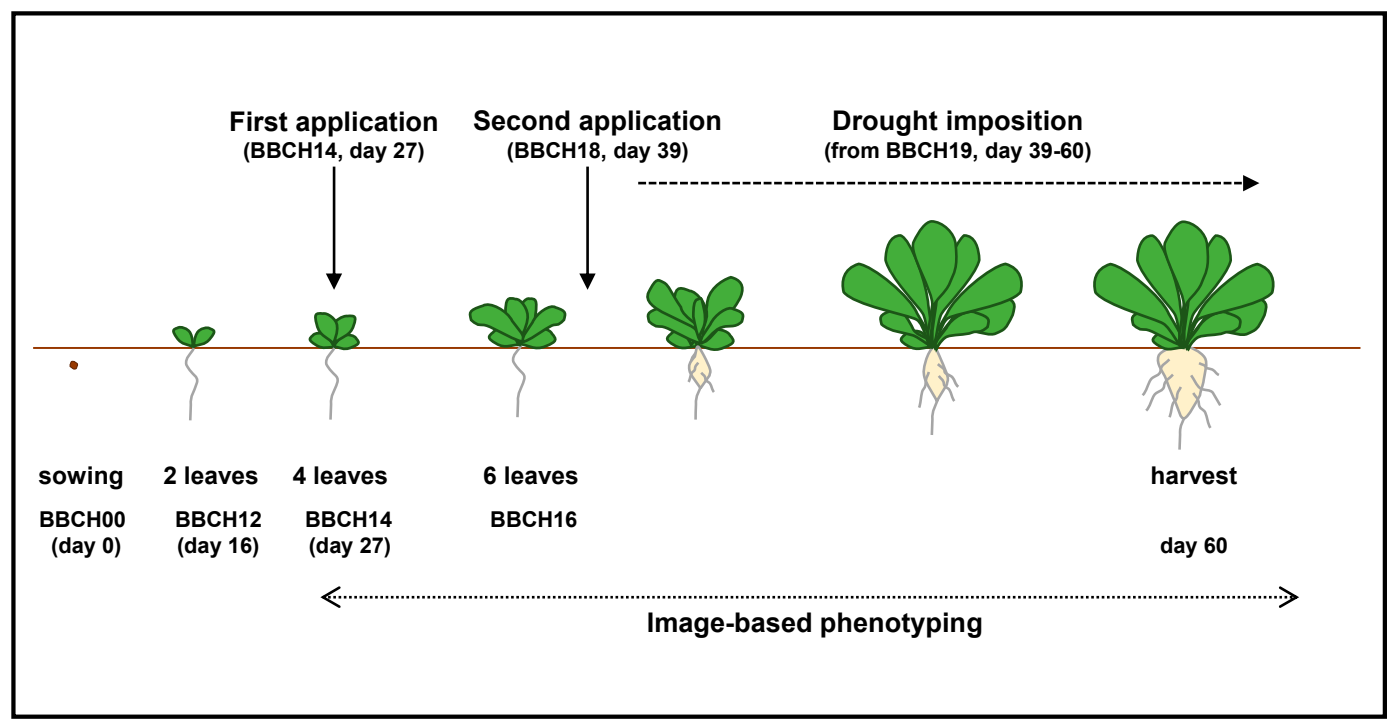

Figure 7. Schematic representation of experimental design. After seed germination, the seedlings were grown for 8 weeks in the Roullier high-throughput plant phenotyping platform. Foliar application of $\mathrm{Ca}^{2+}$ was supplied twice at BBCH14 and BBCH18, each time with a dose of $5 \mathrm{~L} \mathrm{ha}^{-1}$ corresponding to $540 \mathrm{~g} \mathrm{Ca} \mathrm{ha}^{-1}$. Drought stress (30\% field capacity) was imposed 2 days after the second application of $\mathrm{Ca}^{2+}$ for a duration of 3 weeks, while control plants were kept in $90 \%$ of field capacity. From BBCH14 till end of the experiment, image-based phenotyping was applied every 4 days. All plants were harvested at 60 days after sowing for different physiological, biochemical, and molecular analyses.

From BBCH14 (Biologische Bundesanstalt Bundessortenamt und Chemische Industrie) [79] till the end of the experiment, plants were monitored in the Roullier high-throughput plant phenotyping platform ( $16 \mathrm{~h}$ day [in greenhouse equipped with high pressure sodium lights] at $22{ }^{\circ} \mathrm{C}$, and $8 \mathrm{~h}$ night at $19{ }^{\circ} \mathrm{C}$ with $70 \%$ relative humidity in the air) where images of each plant were taken by using two imaging units. The first imaging unit was composed of top and side high definition red-green-blue (RGB) cameras and light-emitting diode (LED) light system (5500 K $\pm 500 \mathrm{~K}$ ). The second imaging unit was composed of a thermal camera, 2-CCD (charge-coupled device) camera (near-infrared and color sensors) and LED light systems ( $5500 \mathrm{~K} \pm 500 \mathrm{~K}$ and $850 \mathrm{~nm}$ ). For all three color images of each plant, we used a customized segmentation algorithm (unpublished) to extract the masks of the plants and remove the background. Mathematical morphology algorithms were applied to filter artefacts according to the quality of the segmentation. Then the masks were applied on the near infrared reflectance (NIR) images and on the thermal files. For the thermal data, an image registration algorithm was used to transform the mask to fit these data. Once all the images were segmented, projected areas for top and side views, as well as the width and height for side views, were calculated. All plants were harvested at 60 days after sowing for different physiological, biochemical, and molecular analyses. 


\subsection{Determination of Root and Shoot Biomass}

For determination of biomass, the fresh beetroot was harvested and weighed. One part of the samples was immediately frozen in liquid $\mathrm{N}_{2}$ and the other part was dried in an oven at $70{ }^{\circ} \mathrm{C}$ for dry matter determination. In parallel, all leaves were harvested and treated the same way.

\subsection{Determination of Chlorophyll}

Chlorophyll concentration was measured according to Connan [80]. Briefly, $25 \mathrm{mg}$ of fresh material was incubated with $0.5 \mathrm{~mL}$ of acetone and sonicated for $10 \mathrm{~min}$. After centrifugation at 10,000 rpm at $4{ }^{\circ} \mathrm{C}$ for $10 \mathrm{~min}$, the supernatant was transferred to a new tube. A second extraction was performed on the pellet with $0.5 \mathrm{~mL}$ of acetone following the same protocol. The two supernatants were collected in the same tube and evaporated under nitrogen flow. Pellet was re-suspended in $1 \mathrm{~mL}$ of methanol and the absorbance was determined at 632,652, 665, and $750 \mathrm{~nm}$.

\subsection{Determination of Mineral Elements}

Elemental analysis was performed according to Maillard et al. [81] in the PLATIN' (Plateau d'Isotopie de Normandie) core facility. Elements were quantified by high-resolution inductively coupled plasma mass spectrometry (HR ICP-MS, Thermo Scientific, Element 2TM) with prior microwave acid sample digestion (Multiwave ECO, Anton Paar, les Ulis, France) (800 $\mu \mathrm{L}$ of concentrated $\mathrm{HNO}_{3}$, $200 \mu \mathrm{L}$ of $\mathrm{H}_{2} \mathrm{O}_{2}$, and $1 \mathrm{~mL}$ of Milli-Q water for $40 \mathrm{mg} \mathrm{DW}$ ). For the determination by high resolution inductively coupled plasma mass spectrometry (HR ICP-MS) all the samples were spiked with two internal-standard solutions of gallium and rhodium for final concentrations of 10 and $2 \mu \mathrm{g} \mathrm{L}^{-1}$, respectively, diluted to $50 \mathrm{~mL}$ with Milli-Q water to obtain solutions containing $2.0 \%(v / v)$ of nitric acid, then filtered at $0.45 \mu \mathrm{m}$ using a teflon filtration system (Filtermate, Courtage Analyses Services, Mont-Saint-Aignan, France). Quantification of each element was performed using external standard calibration curves.

Analysis of N was performed using an elemental FLASH 2000 CHNS analyzer (Thermo Scientific, Waltham, MA, USA) according to manufacturer's instructions from $2.5 \mathrm{mg}$ of homogenized and lyophilized plant material.

\subsection{Determination of Primary Metabolites}

Soluble sugar determination was undertaken according to the method described by Kim et al., 2013 [82]. Ten mg lyophilized shoot material was homogenized in liquid nitrogen, dissolved in $0.75 \mathrm{~mL}$ of $80 \%(v / v)$ ethanol, and incubated at $80{ }^{\circ} \mathrm{C}$ for $30 \mathrm{~min}$. Crude extracts were decanted for $15 \mathrm{~min}$ at retention time (RT), centrifuged at $14,000 \mathrm{rpm}$ for $10 \mathrm{~min}$ at $4{ }^{\circ} \mathrm{C}$, and concentrated in a Speed Vac concentrator (Thermo Scientific) at $45^{\circ} \mathrm{C}$ for $180 \mathrm{~min}$. The pellet was re-suspended in $0.75 \mathrm{~mL}$ deionized water and incubated at $80{ }^{\circ} \mathrm{C}$ for $30 \mathrm{~min}$. After centrifugation, the second supernatant was added to the first, concentrated and resuspended in $0.5 \mathrm{~mL}$ of double distilled water $\left(\mathrm{ddH}_{2} \mathrm{O}\right)$. Hexokinase (HK), phosphoglucoisomerase (PGI), and beta-fructosidase were added successively to measure glucose (Glc), fructose (Fru), and sucrose (Suc), as described in Kim et al., 2013.

For amino acid determination, $10 \mathrm{mg}$ lyophilized dry matter was extracted with a solution containing $400 \mu \mathrm{L}$ of $\mathrm{MeOH}$ and $0.250 \mathrm{nmol} / \mu \mathrm{L}$ Norvaline, which was used as the internal standard (Sigma Aldrich, St. Louis, MO, USA). Extract was stirred for $15 \mathrm{~min}$, and was then re-suspended with $200 \mu \mathrm{L}$ of chloroform (agitation for $5 \mathrm{~min}$ ) and $400 \mu \mathrm{L}$ of $\mathrm{ddH}_{2} \mathrm{O}$. After centrifugation $\left(12,000 \mathrm{rpm}, 10^{\circ} \mathrm{C}\right.$, $5 \mathrm{~min}$ ), the supernatant was recovered, evaporated, and dissolved in $100 \mu \mathrm{L}$ of $\mathrm{ddH}_{2} \mathrm{O}$. Derivatization was performed using an Ultra Derivatization Kit AccQ tag, following the manufacturer's protocol (Waters Corp, Milford, MA, USA). The amino acid profile was determined by using ultra performance liquid chromatography coupled with photodiode array detector (UPLC/PDA) H-Class system with ethylene bridge hybrid (BEH) C18 $100 \times 2.1 \mathrm{~mm}$ column (pore size: $1.7 \mu \mathrm{m}$ ). 
Organic acid analysis was performed as described previously by Ali et al., 2018. Metabolite extraction was conducted using $30 \mathrm{mg}$ of frozen ground fresh leaves and roots, which were weighed in a $2 \mathrm{~mL}$ Eppendorf tubes, then $500 \mu \mathrm{L}$ of cold water/methanol $70: 30 v / v\left(-20^{\circ} \mathrm{C}\right)$ containing $0.1 \%$ of perchloric acid $(v / v)$ solvent were added. Samples were shaken with vortex for $20 \mathrm{~min}$. Then, they were centrifuged using an Eppendorf Centrifuge 5427 R (Eppendorf, Hamburg, Germany) for 20 min $12,700 \mathrm{rpm}$ at $4{ }^{\circ} \mathrm{C}$. Supernatants were collected and introduced in a new $2 \mathrm{~mL}$ Eppendorf tubes. A second extraction was performed adding $500 \mu \mathrm{L}$ of $\mathrm{ddH}_{2} \mathrm{O}+0.1 \%$ perchloric acid $(v / v)$ to leaves and roots, shaken for 5 min with vortex, and centrifuged for 20 min with $12,700 \mathrm{rpm}$ at $4{ }^{\circ} \mathrm{C}$. Supernatants were mixed and centrifuged for $10 \mathrm{~min}$ in order to eliminate suspended particles. Finally, supernatants were diluted three times with $\mathrm{ddH}_{2} \mathrm{O}+0.1 \%$ formic acid $(v / v)$ and introduced in $2 \mathrm{~mL}$ LC-MS vials. Metabolite analysis was achieved using an ultra-high-performance liquid chromatography (UPLC) Acquity H-Class system (Waters Corp, Milford, MA, USA), and high-resolution detection was performed by using a Xevo G2-S QToF mass spectrometer (Waters Corp, Milford, MA, USA) equipped with an electrospray ionization (ESI) source. A Phenomenex Luna®Omega PS C18 (100 $\times 2.1 \mathrm{~mm}, 1.6 \mu \mathrm{m}$ ) column (Torrance, CA, USA) was used to profile the organic acids. The mobile phase, comprising water containing $0.5 \%$ formic acid (A) and methanol: Water (70:30 $v / v)$ containing $0.5 \%$ formic acid (B), was applied with the optimized gradient elution as follows: $100 \%$ A at $0-1 \mathrm{~min}$, $100-20 \% \mathrm{~A}$ at $1-4 \mathrm{~min}, 20-0 \% \mathrm{~A}$ at $4-6.5 \mathrm{~min}, 0 \% \mathrm{~A}$ at $6.5-7.5 \mathrm{~min}, 0-100 \% \mathrm{~A}$ at $7.5-7.9 \mathrm{~min}, 100 \% \mathrm{~A}$ at 7.9-10 $\mathrm{min}$. The flow rate was kept at $0.3 \mathrm{~mL} / \mathrm{min}$, column temperature was maintained at $35^{\circ} \mathrm{C}$. The injection volume for both columns was $10 \mu \mathrm{L}$ and samples were maintained at $10^{\circ} \mathrm{C}$. The ESI source was used in negative ionization, source voltage was set to $2.5 \mathrm{kV}$ and cone voltage was $30 \mathrm{~V}$, whilst source temperature was maintained at $130^{\circ} \mathrm{C}$ with a cone gas flow of $20 \mathrm{~L} / \mathrm{h}$. The desolvation temperature was at $500{ }^{\circ} \mathrm{C}$, with a desolvation gas flow of $900 \mathrm{~L} / \mathrm{h}$. Leucine-Enkephalin was used as lockmass reference, (ion at $\mathrm{m} / \mathrm{z} 556.2771$ in positive mode), which was introduced by a lockspray at 10 $\mu \mathrm{L} \min ^{-1}$ for real-time data calibration. The MSE data were acquired in centroid mode using a scan range 50-800 Da, scan time $0.1 \mathrm{~s}$, resolution was set at 20,000 full width half maximum (FWHM), and a collision energy ramp 40-80 V. GSH and GSSG were determined according to Ali et al., 2018.

Polyamine extraction was achieved using $20 \mathrm{mg}$ of frozen ground leaves that were weighed in a $2 \mathrm{~mL}$ eppendorf tube (Eppendorf, Hamburg, Germany). Extraction was carried out by adding $1 \mathrm{~mL}$ of a solution of $70 \% \mathrm{H} 2 \mathrm{O} / 29 \% \mathrm{MeOH} / 1.0 \%$ formic acid $(v / v / v)$ at $-20{ }^{\circ} \mathrm{C}$ using a Mixer Mill MM 400 (Retsch, Haan, Germany). Next, the tubes were stirred at room temperature for $30 \mathrm{~min}$, and then centrifuged at $4{ }^{\circ} \mathrm{C}$ for $20 \mathrm{~min}(12,500 \mathrm{rpm})$, and the supernatant was transferred into new Eppendorf tubes. The supernatant was transferred to a LC/MS vial for analysis. Polyamines were analyzed by an ultra-high performance liquid chromatography coupled with tandem mass spectrometry (UHPLC-MS/MS) system. The separation and detection were achieved using a Nexera X2 UHPLC system (Shimadzu, Kyoto, Japan) coupled to a QTrap 6500+ mass spectrometer (Sciex, Concord, ON, Canada) equipped with an IonDriveTM turbo V electrospray (ESI) source.

\subsection{RNA Extraction and Gene Expression Analysis}

The root and leaf samples $(100 \mathrm{mg})$ of sugar beet plants were ground to a fine powder in the presence of liquid nitrogen and total RNA was extracted using a Nucleospin@8 RNA kit following the manufacturer's protocol (Macherey-Nagel, Düren, Germany). The quality and yield of all RNA samples were analyzed and checked in a 4200 Tapestation (Agilent Technologies, Santa Clara, CA, USA), followed by DNase treatment and cDNA synthesis from $1 \mu \mathrm{g}$ RNA using iScript ${ }^{\mathrm{TM}}$ gDNA clear cDNA synthesis kit (Bio-Rad, Hercules, CA, USA). Quantitative RT-PCR (qPCR) analysis was performed in a total volume of $10 \mu \mathrm{L}$ using Universal SYBR Green Supermix (Bio-Rad, Hercules, CA, USA) in Real-Time PCR Detection System (Bio-Rad, Hercules, CA, USA). The qPCR reactions were performed in technical triplicates using independent cDNA reactions for each biological replicate and $300 \mathrm{nM}$ of gene-specific primer pairs. Specific primers for all candidate genes were designed using Primer3 software (version 0.4.0) and are listed in Supplementary Table S2. The thermal cycler protocol was 
$98^{\circ} \mathrm{C}$ for $3 \mathrm{~min}, 40$ cycles of $98^{\circ} \mathrm{C}$ for $15 \mathrm{~s}, 60^{\circ} \mathrm{C}$ for $30 \mathrm{~s}, 72{ }^{\circ} \mathrm{C}$ for $15 \mathrm{~s}$, and a final 5 -min extension at $72{ }^{\circ} \mathrm{C}$. The expression of all candidate genes were normalized against three sugar beet reference genes, namely, EF1 $\alpha, 18 \operatorname{SrRNA}$, and $\beta$-tubulin. All qPCR expression data were acquired and analyzed using CFX Maestro Software Version 1.0 (Bio-Rad, Hercules, CA, USA).

\subsection{Statistical Analysis}

Data are represented as mean \pm standard deviation (SD) or standard error of the mean (SEM) for $n=6$. The analysis of variance (ANOVA) and the post-hoc Student-Newman-Keuls (SNK) (R software) were employed to analyze the data and marked by different letters when significantly different $(p<0.05)$.

\section{Conclusions}

In our study, we show that the foliar application of $\mathrm{Ca}^{2+}$ to sugar beet plants exposed to drought stress regulates plant mineral status $(\mathrm{Mg}$ and $\mathrm{Si}$ ), sugar metabolism both at metabolic and transcriptional levels, influences plant metabolism and balanced redox state and thus increased drought stress tolerance. In leaves, foliar application of $\mathrm{Ca}^{2+}$ increased plant dry matter as well as chlorophyll levels under drought. Also, the application of $\mathrm{Ca}^{2+}$ enhanced the concentrations of $\mathrm{Mg}$ and $\mathrm{Si}$ which could positively impact the sugar synthesis and transcriptionally regulate the genes involved in sugar transport (BvSUC3 and BvTST3). Additionally, plants showed a strong tolerance to drought induced-oxidative stress by regulating glutathione pools (lower GSSG/GSH ratio) which was further supported by a higher putrescine level and lower GABA concentrations. In beetroot, the remarkable effect of $\mathrm{Ca}^{2+}$ was higher Suc storage under drought stress. Altogether, our findings demonstrate that foliar application of $\mathrm{Ca}^{2+}$ enabled drought-stressed sugar beet plants to cope better with stress by maintaining efficient shoot growth and allocating relatively more Suc to the beetroots (Figure 8).

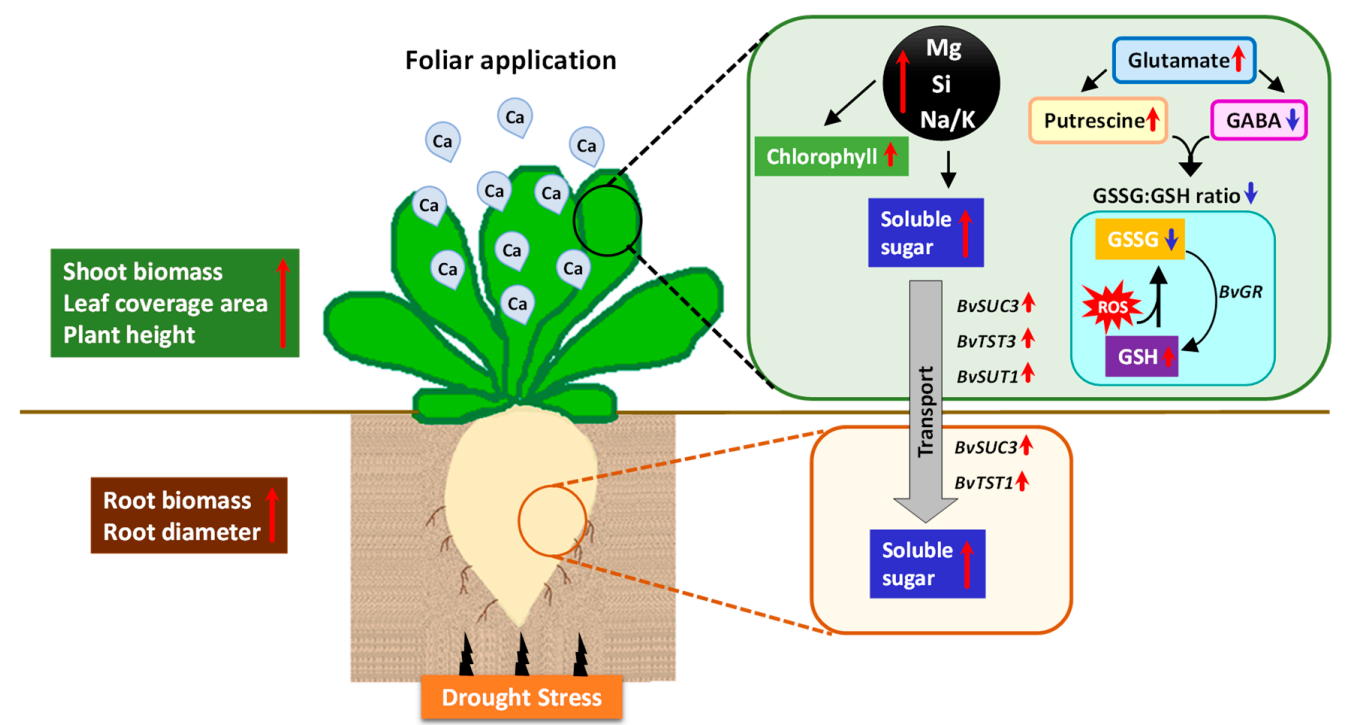

Figure 8. Schematic model representing the regulatory role of $\mathrm{Ca}^{2+}$ on the response of sugar beet plants to drought stress. $\mathrm{Ca}^{2+}$ treated sugar beet plants effectively tolerated drought stress by regulating the concentration of $\mathrm{Mg}$ and $\mathrm{Si}$ in the leaves which consequently enhanced sugar metabolism both at the metabolic and transcriptional level. $\mathrm{Ca}^{2+}$ also increased the $\mathrm{Na} / \mathrm{K}$ ratio in leaf displaying the possible role of $\mathrm{Na}$ in osmotic adjustment under drought stress. Shoots displayed increased leaf coverage area, higher biomass, and higher chlorophyll, along with increase in the beetroot diameter and beetroot biomass. Additionally, the lower GSSG/GSH ratio, higher putrescine levels, and reduced GABA level clearly showed that the $\mathrm{Ca}^{2+}$ treated plants were able to efficiently tolerate drought-induced oxidative stress. (Red arrows = increase/upregulation, blue arrows = decrease/downregulation). 
Supplementary Materials: Supplementary materials can be found at http:/www.mdpi.com/1422-0067/20/15/ 3777/s1.

Author Contributions: Conceptualization, S.A.H. and S.P.; Data curation, N.A.; Formal analysis, E.R., N.A. and B.B.; Investigation, S.A.H.; Project administration, S.A.H.; Software, N.A. and B.B.; Validation, S.A.H.; Visualization, B.B.; Writing—original draft, S.A.H.; Writing—review \& editing, S.A.H., E.R., S.P., N.A. and J.-C.Y.

Funding: This research received no external funding.

Acknowledgments: We thank Noemi Armal, Amandine Nedellec, and Sibylle Gremaud for their excellent technical assistance. We thank Adrian Schwarzenberg for supervising the metabolite analysis. We also thank Frank Jamois for providing and Allan Quelen and Alexandre Gaillard for preparing and formulating the Ca product. We are most grateful to PLATIN' (Plateau d'Isotopie de Normandie) core facility for all element and isotope analysis used in this study.

Conflicts of Interest: The authors have no conflict of interest to declare.

\section{Abbreviations}

DAA Day after application

Glu Glucose

Fru Fructose

Suc Sucrose

GABA Gamma-aminobutyric acid

Put Putrescine

GSH Reduced glutathione

GSSG Oxidized Glutathione

$B v C M O \quad$ Choline monooxygenase

BvDREB2A Dehydration responsive element-binding 2A

\section{References}

1. Mubarak, M.U.; Zahir, M.; Ahmad, S.; Wakeel, A. Sugar beet yield and industrial sugar contents improved by potassium fertilization under scarce and adequate moisture conditions. J. Integr. Agric. 2016, 15, 2620-2626. [CrossRef]

2. Hermans, C.; Bourgis, F.; Faucher, M.; Strasser, R.J.; Delrot, S.; Verbruggen, N. Magnesium deficiency in sugar beet alters sugar partitioning and phloem loading in young mature leaves and phloem loading in young mature leaves. Planta 2005, 220, 541-549. [CrossRef] [PubMed]

3. Jung, B.; Ludewig, F.; Schulz, A.; Meißner, G.; Wöstefeld, N.; Flügge, U.I.; Pommerrenig, B.; Wirsching, P.; Sauer, N.; Koch, W.; et al. Identification of the transporter responsible for sucrose accumulation in sugar beet taproots. Nat. Plants 2015, 1, 14001. [CrossRef] [PubMed]

4. Hoffmann, C.M. Sucrose accumulation in sugar beet under drought stress. J. Agron. Crop Sci. 2010, 196, 243-252. [CrossRef]

5. Pilon-Smits, E.A.H.; Terry, N.; Sears, T.; Van Dun, K. Enhanced drought resistance in fructan-producing sugar beet. Plant Physiol. Biochem. 1999, 37, 313-317. [CrossRef]

6. Chołuj, D.; Wiśniewska, A.; Szafrański, K.M.; Cebula, J.; Gozdowski, D.; Podlaski, S. Assessment of the physiological responses to drought in different sugar beet genotypes in connection with their genetic distance. J. Plant Physiol. 2014, 171, 1221-1230. [CrossRef] [PubMed]

7. Shaw, B.; Thomas, T.H.; Cooke, D.T. Responses of sugar beet (Beta vulgaris L.) to drought and nutrient. Plant Growth Regul. 2002, 37, 77-83. [CrossRef]

8. Hosseini, S.A.; Hajirezaei, M.R.; Seiler, C.; Sreenivasulu, N.; von Wirén, N. A Potential Role of Flag Leaf Potassium in Conferring Tolerance to Drought-Induced Leaf Senescence in Barley. Front. Plant Sci. 2016, 7, 1-12. [CrossRef]

9. Marschner, H.; Marschner, P. Marschner's Mineral Nutrition of Higher Plants; Academic Press: San Diego, CA, USA, 2012; ISBN 9780123849052.

10. Lebaudy, A.; Vavasseur, A.; Hosy, E.; Dreyer, I.; Leonhardt, N.; Thibaud, J.-B.; Véry, A.-A.; Simonneau, T.; Sentenac, H. Plant adaptation to fluctuating environment and biomass production are strongly dependent on guard cell potassium channels. Proc. Natl. Acad. Sci. USA 2008, 105, 5271-5276. [CrossRef] 
11. Chan, K.X.; Wirtz, M.; Phua, S.Y.; Estavillo, G.M.; Pogson, B.J. Balancing metabolites in drought: The sulfur assimilation conundrum. Trends Plant Sci. 2013, 18, 18-29. [CrossRef]

12. Shabbir, R.N.; Waraich, E.A.; Ali, H.; Nawaz, F.; Ashraf, M.Y.; Ahmad, R.; Awan, M.I.; Ahmad, S.; Irfan, M.; Hussain, S.; et al. Supplemental exogenous NPK application alters biochemical processes to improve yield and drought tolerance in wheat (Triticum aestivum L.). Environ. Sci. Pollut. Res. 2016, 23, 2651-2662. [CrossRef]

13. Hermans, C.; Hammond, J.P.; White, P.J.; Verbruggen, N. How do plants respond to nutrient shortage by biomass allocation? Trends Plant Sci. 2006, 11, 610-617. [CrossRef]

14. Romheld, V.; Kirkby, E.A. Research on potassium in agriculture: Needs and prospects. Plant Soil 2010, 335, 155-180. [CrossRef]

15. Hochmal, A.K.; Schulze, S.; Trompelt, K.; Hippler, M. Calcium-dependent regulation of photosynthesis. Biochim. Biophys. Acta 2015, 1847, 993-1003. [CrossRef]

16. Amunts, A.; Toporik, H.; Borovikova, A.; Nelson, N. Structure determination and improved model of plant photosystem I. J. Biol. Chem. 2010, 285, 3478-3486. [CrossRef]

17. Ettinger, W.F.; Clear, A.M.; Fanning, K.J.; Peck, M. Lou Identification of a $\mathrm{Ca}^{2+} / \mathrm{H}^{+}$antiport in the plant chloroplast thylakoid membrane. Plant Physiol. 1999, 119, 1379-1386. [CrossRef]

18. Ferreira, K.N.; Iverson, T.M.; Maghlaoui, K.; Barber, J.; Iwata, S. Architecture of the photosynthetic oxygen-evolving center. Science 2004, 303, 1831-1838. [CrossRef]

19. Sai, J.; Johnson, C.H. Dark-stimulated calcium ion fluxes in the chloroplast stroma and cytosol. Plant Cell 2002, 14, 1279-1291. [CrossRef]

20. Vainonen, J.P.; Sakuragi, Y.; Stael, S.; Tikkanen, M.; Allahverdiyeva, Y.; Paakkarinen, V.; Aro, E.; Suorsa, M.; Scheller, H.V.; Vener, A.V.; et al. Light regulation of CaS, a novel phosphoprotein in the thylakoid membrane of Arabidopsis thaliana. FEBS J. 2008, 275, 1767-1777. [CrossRef]

21. Huang, K.; Peng, L.; Liu, Y.; Yao, R.; Liu, Z.; Li, X.; Yang, Y.; Wang, J. Arabidopsis calcium-dependent protein kinase AtCPK1 plays a positive role in salt/drought-stress response. Biochem. Biophys. Res. Commun. 2018, 498, 92-98. [CrossRef]

22. Naeem, M.; Naeem, M.S.; Ahmad, R.; Ihsan, M.Z.; Ashraf, M.Y.; Hussain, Y.; Fahad, S. Foliar calcium spray confers drought stress tolerance in maize via modulation of plant growth, water relations, proline content and hydrogen peroxide activity. Arch. Agron. Soil Sci. 2018, 64, 116-131. [CrossRef]

23. Podlešáková, K.; Ugena, L.; Spíchal, L.; Doležal, K.; De Diego, N. Phytohormones and polyamines regulate plant stress responses by altering GABA pathway. New Biotechnol. 2019, 48, 53-65. [CrossRef]

24. Maillard, A.; Ali, N.; Schwarzenberg, A.; Jamois, F.; Yvin, J.-C.; Hosseini, S.A. Silicon transcriptionally regulates sulfur and ABA metabolism and delays leaf senescence in barley under combined sulfur deficiency and osmotic stress. Environ. Exp. Bot. 2018, 155, 394-410. [CrossRef]

25. Cheong, Y.H.; Pandey, G.K.; Grant, J.J.; Batistic, O.; Li, L.; Kim, B.G.; Lee, S.C.; Kudla, J.; Luan, S. Two calcineurin B-like calcium sensors, interacting with protein kinase CIPK23, regulate leaf transpiration and root potassium uptake in Arabidopsis. Plant J. 2007, 52, 223-239. [CrossRef]

26. Avramova, V.; Nagel, K.A.; Abdelgawad, H.; Bustos, D.; Duplessis, M.; Fiorani, F.; Beemster, G.T.S. Screening for drought tolerance of maize hybrids by multi-scale analysis of root and shoot traits at the seedling stage. J. Exp. Bot. 2016, 67, 2453-2466. [CrossRef]

27. Karaba, A.; Dixit, S.; Greco, R.; Aharoni, A.; Trijatmiko, K.R.; Marsch-Martinez, N.; Krishnan, A.; Nataraja, K.N.; Udayakumar, M.; Pereira, A. Improvement of water use efficiency in rice by expression of HARDY, an Arabidopsis drought and salt tolerance gene. Proc. Natl. Acad. Sci. USA 2007, 104, 15270-15275. [CrossRef]

28. Barnabás, B.; Jäger, K.; Fehér, A. The effect of drought and heat stress on reproductive processes in cereals. Plant Cell Environ. 2008, 31, 11-38. [CrossRef]

29. Cho, Y.-H.; Hong, J.-W.; Kim, E.-C.; Yoo, S.-D. Regulatory Functions of SnRK1 in Stress-Responsive Gene Expression and in Plant Growth and Development. Plant Physiol. 2012, 158, 1955-1964. [CrossRef]

30. Artyszak, A.; Gozdowski, D.; Kucińska, K. The Effect of Calcium and Silicon Foliar Fertilization in Sugar Beet. Sugar Tech 2016, 18, 109-114. [CrossRef]

31. Hu, A.Y.; Che, J.; Shao, J.F.; Yokosho, K.; Zhao, X.Q.; Shen, R.F.; Ma, J.F. Silicon accumulated in the shoots results in down-regulation of phosphorus transporter gene expression and decrease of phosphorus uptake in rice. Plant Soil 2018, 423, 317-325. [CrossRef] 
32. Mir, R.R.; Zaman-Allah, M.; Sreenivasulu, N.; Trethowan, R.; Varshney, R.K. Integrated genomics, physiology and breeding approaches for improving drought tolerance in crops. Theor. Appl. Genet. 2012, 125, 625-645. [CrossRef]

33. Gimeno, V.; Díaz-López, L.; Simón-Grao, S.; Martínez, V.; Martínez-Nicolás, J.J.; García-Sánchez, F. Foliar potassium nitrate application improves the tolerance of Citrus macrophylla L. seedlings to drought conditions. Plant Physiol. Biochem. 2014, 83, 308-315. [CrossRef]

34. Hu, W.; Tian, S.B.; Di, Q.; Duan, S.H.; Dai, K. Effects of exogenous calcium on mesophyll cell ultrastructure, gas exchange, and photosystem II in tobacco (Nicotiana tabacum Linn.) under drought stress. Photosynthetica 2018, 56, 1204-1211. [CrossRef]

35. Hu, Y.; Burucs, Z.; Schmidhalter, U. Effect of foliar fertilization application on the growth and mineral nutrient content of maize seedlings under drought and salinity. Soil Sci. Plant Nutr. 2008, 54, 133-141. [CrossRef]

36. White, P.J.; Broadley, M.R. Calcium in plants. Ann. Bot. 2003, 92, 487-511. [CrossRef]

37. Hayes, P.E.; Clode, P.L.; Guilherme Pereira, C.; Lambers, H. Calcium modulates leaf cell-specific phosphorus allocation in Proteaceae from south-western Australia. New Phytol. 2019, 221, 764-777. [CrossRef]

38. Slama, I.; Ghnaya, T.; Messedi, D.; Hessini, K.; Labidi, N.; Savoure, A.; Abdelly, C. Effect of sodium chloride on the response of the halophyte species Sesuvium portulacastrum grown in mannitol-induced water stress. J. Plant Res. 2007, 120, 291-299. [CrossRef]

39. Ma, Q.; Yue, L.J.; Zhang, J.L.; Wu, G.Q.; Bao, A.K.; Wang, S.M. Sodium chloride improves photosynthesis and water status in the succulent xerophyte Zygophyllum xanthoxylum. Tree Physiol. 2012, 32, 4-13. [CrossRef]

40. Wu, G.Q.; Feng, R.J.; Liang, N.; Yuan, H.J.; Sun, W.-B. Sodium chloride stimulates growth and alleviates sorbitol-induced osmotic stress in sugar beet seedlings. Plant Growth Regul. 2014, 75, 307-316. [CrossRef]

41. Wakeel, A.; Farooq, M.; Qadir, M.; Schubert, S. Potassium Substitution by Sodium in Plants. CRC. Crit. Rev. Plant Sci. 2011, 30, 401-413. [CrossRef]

42. Guo, W.; Chen, S.; Hussain, N.; Cong, Y.; Liang, Z.; Guo, W.; Chen, S.; Hussain, N.; Cong, Y.; Liang, Z.; et al. Magnesium stress signaling in plant: Just a beginning. Plant Signal. Behav. 2015, 10, e992287. [CrossRef]

43. Hermans, C.; Verbruggen, N. Physiological characterization of Mg deficiency in Arabidopsis thaliana. J. Exp. Bot. 2005, 56, 2153-2161. [CrossRef]

44. Dordas, C. Foliar application of calcium and magnesium improves growth, yield, and essential oil yield of oregano (Origanum vulgare ssp. hirtum). Ind. Crops Prod. 2009, 29, 599-608. [CrossRef]

45. Cooke, J.; Leishman, M.R. Consistent alleviation of abiotic stress with silicon addition: A meta-analysis. Funct. Ecol. 2016, 30, 1340-1357. [CrossRef]

46. Kang, J.; Zhao, W.; Zhu, X. Silicon improves photosynthesis and strengthens enzyme activities in the C3 succulent xerophyte Zygophyllum xanthoxylum under drought stress. J. Plant Physiol. 2016, 199, 76-86. [CrossRef]

47. Ali, N.; Schwarzenberg, A.; Yvin, J.-C.; Hosseini, S.A. Regulatory Role of Silicon in Mediating Differential Stress Tolerance Responses in Two Contrasting Tomato Genotypes Under Osmotic Stress. Front. Plant Sci. 2018, 9, 1-16. [CrossRef]

48. Hosseini, S.A.; Maillard, A.; Hajirezaei, M.R.; Ali, N.; Schwarzenberg, A.; Jamois, F.; Yvin, J.-C. Induction of Barley Silicon Transporter HvLsi1 and HvLsi2, increased silicon concentration in the shoot and regulated Starch and ABA Homeostasis under Osmotic stress and Concomitant Potassium Deficiency. Front. Plant Sci. 2017, 8, 1359. [CrossRef]

49. Hattori, T.; Inanaga, S.; Araki, H.; An, P.; Morita, S.; Luxová, M.; Lux, A. Application of silicon enhanced drought tolerance in Sorghum bicolor. Physiol. Plant. 2005, 123, 459-466. [CrossRef]

50. Guntzer, F.; Keller, C.; Meunier, J.D. Benefits of plant silicon for crops: A review. Agron. Sustain. Dev. 2012, 32, 201-213. [CrossRef]

51. Haddad, C.; Arkoun, M.; Jamois, F.; Schwarzenberg, A.; Yvin, J.-C.; Etienne, P.; Laîné, P. Silicon Promotes Growth of Brassica napus L. and Delays Leaf Senescence Induced by Nitrogen Starvation. Front. Plant Sci. 2018, 9, 516. [CrossRef]

52. Hosseini, S.A.; Rad, S.N.; Ali, N.; Yvin, J.-C. The Ameliorative Effect of Silicon on Maize Plants Grown in Mg-Deficient Conditions. Int. J. Mol. Sci. 2019, 20, 969. [CrossRef]

53. Bloch, D.; Hoffmann, C.M.; Märländer, B. Impact of water supply on photosynthesis, water use and carbon isotope discrimination of sugar beet genotypes. Eur. J. Agron. 2006, 24, 218-225. [CrossRef] 
54. Monti, A.; Brugnoli, E.; Scartazza, A.; Amaducci, M.T. The effect of transient and continuous drought on yield, photosynthesis and carbon isotope discrimination in sugar beet (Beta vulgaris L.). J. Exp. Bot. 2006, 57, 1253-1262. [CrossRef]

55. Mäck, G.; Hoffmann, C.M. Organ-specific adaptation to low precipitation in solute concentration of sugar beet (Beta vulgaris L.). Eur. J. Agron. 2006, 25, 270-279. [CrossRef]

56. Silvente, S.; Sobolev, A.P.; Lara, M. Metabolite adjustments in drought tolerant and sensitive soybean genotypes in response to water stress. PLoS ONE 2012, 7, e38554. [CrossRef]

57. Taji, T.; Ohsumi, C.; Iuchi, S.; Seki, M.; Kasuga, M.; Kobayashi, M.; Yamaguchi-Shinozaki, K.; Shinozaki, K. Important roles of drought- and cold-inducible genes for galactinol synthase in stress tolerance in Arabidopsis thaliana. Plant J. 2002, 29, 417-426. [CrossRef]

58. Wingler, A.; Roitsch, T. Metabolic regulation of leaf senescence: Interactions of sugar signalling with biotic and abiotic stress responses. Plant Biol. 2008, 10, 50-62. [CrossRef]

59. Pieters, A.J.; Paul, M.J.; Lawlor, D.W. Low sink demand limits photosynthesis under Pi deficiency. J. Exp. Bot. 2001, 52, 1083-1091. [CrossRef]

60. Cakmak, I.; Hengeler, C.; Marschner, H. Changes in phloem export of sucrose in leaves in response to phosphorus, potassium and magnesium deficiency in bean plants. J. Exp. Bot. 1994, 45, 1251-1257. [CrossRef]

61. Cakmak, I.; Kirkby, E.A. Role of magnesium in carbon partitioning and alleviating photooxidative damage. Physiol. Plant. 2008, 133, 692-704. [CrossRef]

62. Cakmak, I.; Schjoerring, J.K. Special topics in potassium and magnesium research. Physiol. Plant. 2008, 133, 623. [CrossRef]

63. Julius, B.T.; Leach, K.A.; Tran, T.M.; Mertz, R.A.; Braun, D.M. Sugar transporters in plants: New insights and discoveries. Plant Cell Physiol. 2017, 58, 1442-1460. [CrossRef]

64. Casu, R.E.; Rae, A.L.; Nielsen, J.M.; Perroux, J.M.; Bonnett, G.D.; Manners, J.M. Tissue-specific transcriptome analysis within the maturing sugarcane stalk reveals spatial regulation in the expression of cellulose synthase and sucrose transporter gene families. Plant Mol. Biol. 2015, 89, 607-628. [CrossRef]

65. Bihmidine, S.; Julius, B.T.; Dweikat, I.; Braun, D.M. Tonoplast Sugar Transporters (SbTSTs) putatively control sucrose accumulation in sweet sorghum stems. Plant Signal. Behav. 2016, 11, e1117721. [CrossRef]

66. Durand, M.; Porcheron, B.; Hennion, N.; Maurousset, L.; Lemoine, R.; Pourtau, N. Water Deficit Enhances C Export to the Roots in Arabidopsis thaliana Plants with Contribution of Sucrose Transporters in Both Shoot and Roots. Plant Physiol. 2016, 170, 1460-1479. [CrossRef]

67. Noctor, G.; Mhamdi, A.; Foyer, C.H. The Roles of Reactive Oxygen Metabolism in Drought: Not So Cut and Dried. Plant Physiol. 2014, 164, 1636-1648. [CrossRef]

68. Munemasa, S.; Muroyama, D.; Nagahashi, H.; Nakamura, Y.; Mori, I.C.; Murata, Y. Regulation of reactive oxygen species-mediated abscisic acid signaling in guard cells and drought tolerance by glutathione. Front. Plant Sci. 2013, 4, 1-6. [CrossRef]

69. Tripathy, B.C.; Oelmüller, R.; Tripathy, B.C.; Oelmüller, R. Reactive oxygen species generation and signaling in plants. Plant Signal. Behav. 2015, 2324, 1621-1633. [CrossRef]

70. Ahmad, N.; Malagoli, M.; Wirtz, M.; Hell, R. Drought stress in maize causes differential acclimation responses of glutathione and sulfur metabolism in leaves and roots. BMC Plant Biol. 2016, 16, 247. [CrossRef]

71. Foyer, C.H.; Noctor, G. Ascorbate and glutathione: The heart of the redox hub. Plant Physiol. 2011, 155, 2-18. [CrossRef]

72. Noctor, G.; Mhamdi, A.; Chaouch, S.; Han, Y.; Neukermans, J.; Marquez-Garcia, B.; Queval, G.; Foyer, C.H. Glutathione in plants: An integrated overview. Plant Cell Environ. 2012, 35, 454-484. [CrossRef]

73. Loggini, B.; Scartazza, A.; Brugnoli, E.; Navari-Izzo, F. Antioxidative defense system, pigment composition, and photosynthetic efficiency in two wheat cultivars subjected to drought. Plant Physiol. 1999, 119, 1091-1100. [CrossRef]

74. Pyngrope, S.; Bhoomika, K.; Dubey, R.S. Reactive oxygen species, ascorbate-glutathione pool, and enzymes of their metabolism in drought-sensitive and tolerant indica rice (Oryza sativa L.) seedlings subjected to progressing levels of water deficit. Protoplasma 2013, 250, 585-600. [CrossRef]

75. Liu, J.-H.; Wang, W.; Wu, H.; Gong, X.; Moriguchi, T. Polyamines function in stress tolerance: From synthesis to regulation. Front. Plant Sci. 2015, 6, 1-10. [CrossRef]

76. Chen, D.; Cao, B.; Qi, L.; Yin, L.; Wang, S.; Deng, X. Silicon-moderated K-deficiency-induced leaf chlorosis by decreasing putrescine accumulation in sorghum. Ann. Bot. 2016, 118, 305-315. [CrossRef] 
77. Liu, C.; Zhao, L.; Yu, G. The dominant glutamic acid metabolic flux to produce $\gamma$-amino butyric acid over proline in nicotiana tabacum leaves under water stress relates to its significant role in antioxidant activity. J. Integr. Plant Biol. 2011, 53, 608-618. [CrossRef]

78. Majumdar, R.; Barchi, B.; Turlapati, S.A.; Gagne, M.; Minocha, R.; Long, S.; Minocha, S.C. Glutamate, Ornithine, Arginine, Proline, and Polyamine Metabolic Interactions: The Pathway Is Regulated at the Post-Transcriptional Level. Front. Plant Sci. 2016, 7, 1-17. [CrossRef]

79. Meier, U. Growth Stages of Mono-and Dicotyledonous Plants: BBCH Monograph, 2nd ed.; Federal Biological Research Centre for Agriculture and Forestry, Ed.; Blackwell Wissenschafts-Verlag: Berlin, Germany, 2011.

80. Connan, S. Spectrophotometric Assays of Major Compounds Extracted from Algae. In Methods in Molecular Biology; Humana Press: New York, NY, USA, 2015; Volume 1308, pp. 75-101.

81. Maillard, A.; Etienne, P.; Diquélou, S.; Trouverie, J.; Billard, V.; Yvin, J.C.; Ourry, A. Nutrient deficiencies modify the ionomic composition of plant tissues: A focus on cross-talk between molybdenum and other nutrients in Brassica napus. J. Exp. Bot. 2016, 67, 5631-5641. [CrossRef]

82. Kim, Y.M.; Heinzel, N.; Giese, J.O.; Koeber, J.; Melzer, M.; Rutten, T.; Von Wirén, N.; Sonnewald, U.; Hajirezaei, M.R. A dual role of tobacco hexokinase 1 in primary metabolism and sugar sensing. Plant Cell Environ. 2013, 36, 1311-1327. [CrossRef]

(C) 2019 by the authors. Licensee MDPI, Basel, Switzerland. This article is an open access article distributed under the terms and conditions of the Creative Commons Attribution (CC BY) license (http://creativecommons.org/licenses/by/4.0/). 